\title{
COARCTATION OF THE AORTA
}

\author{
BY \\ MAURICE CAMPBELL AND S. SUZMAN \\ From the Cardiac Department, Guy's Hospital, and the National Heart Hospital \\ Received May 2, 1947
}

The collateral circulation in the chest wall, when well-developed, may be the most striking feature of coarctation of the aorta. It was not, however, often recorded by the good clinicians of the past though they had a wide'knowledge of the subject in the post-mortem room (Fawcett, 1905). Coarctation is not very uncommon, as hospital post-mortem statistics show that it occurs in about one case in a thousand (Fawcett, 1905, and Evans, 1933, and Blackford, 1926). In spite of this it is still frequently missed probably because in many cases the collateral circulation is not as obvious as it is expected to be, and because the insistence of Lewis (1933) on the importance of the poor femoral pulse is still not remembered often enough.

In infancy, it is rarely diagnosed in life, and in children less often than in adults though the number of reported cases is increasing. This is partly because the blood pressure does not rise greatly for some years and because the collateral circulation does not become evident in the thoracic wall till later. Sheldon (1945) states " a collateral circulation does not develop until about six or seven years of age, but before this the diagnosis can be made with assurance, in the presence of the other physical signs-raised blood pressure in the arms with no femoral pulse and a systolic murmur at the base of the heart."

Our main objects in this paper are to record the development of these changes in some young patients watched over several years, to describe a new sign for demonstrating the collateral circulation, to discuss some theoretical aspects, and to emphasize the points that we think likely to help in the diagnosis.

The cardinal points in the diagnosis are:

(1) A raised blood pressure in the upper half of the body.

(2) Forcible pulsation of the arteries in the neck, sometimes simulating aortic incompetence; this was obvious in 12 of our 15 cases and was sometimes the first suggestion of any abnormality: it should direct attention to the high blood pressure in the arms when this has not been taken as a routine.

(3) Feeble or absent pulsation in the femoral arteries and the abdominal aorta, and a low blood pressure in the legs with a high or relatively high pressure in the arms.

(4) The collateral circulation shown round the scapulæ, on the side of the chest wall, and over the anterior abdominal wall.

(5) The collateral circulation shown by notching of the ribs on X-ray examination.

(6) A systolic murmur (rarely with a thrill) at the base of the heart and often in the back, sometimes with a diastolic murmur.

The diagnosis is most likely to be made in the less obvious cases if the femoral pulse is felt for in every case with high blood pressure, or with obvious arterial pulsation in the neck, or with an unexplained systolic (or diastolic) murmur at the base of the heart. Although the femoral pulse is often difficult to feel, there are as a rule no symptoms of any gross circulatory deficiency in the legs because an adequate amount of blood flows in by devious channels in spite of the absence of a clear pulse wave transmitted directly to the femoral arteries. Symptoms of slight circulatory deficiency may be found on more careful questioning, especially 
aching in the legs after marches or long walks. As soon as there is doubt about the femoral pulse the blood pressure should be taken in the legs.

The collateral circulation will be considered first and then the notching of the ribs; next the size of the heart and the murmurs; next the blood pressure and such evidence as we have been able to obtain of the time of development of the rise of blood pressure; and finally the prognosis.

\section{The Collateral Circulation}

We wish to describe a new sign for demonstrating this and to bring forward some evidence for the time and rate of the development of the superficial collateral circulation and also of the notching of the ribs from infancy to adult life. The collateral circulation was well studied by early workers and there is a model in the Guy's Hospital Museum from a specimen of Wilks dating from 1859. The subject has been fully reviewed by Bramwell and Jones (1941).

When the collateral circulation is not obvious inspection may fail to show the enlarged and tortuous arteries under the skin. The surface should be inspected from all angles in a good light and the hand passed lightly over all likely positions as in this way a small portion of a pulsating artery under the skin will sometimes be revealed. The patient should also be made to bend forward (see later).

The collateral circulation increases with the years, presumably till it reaches a balance with the demands being made on it. After surgical ligature of an artery the collateral circulation seems to reach its maximum within a relatively short period of months. The much longer period of development with coarctation of the aorta suggests that the need for it increases and this is probably mainly because the actual size of the coarctation does not increase in diameter at the same rate as the rest of the aorta, if at all, so that relatively the degree of stenosis increases until the age. when full physical development has been completed.

In all our patients observed over a period of several years increases in the collateral circulation as evidenced by the subcutaneous arteries were noted.

Case 1, aged 7. It was visible and palpable, especially round the scapulæ, when he was first seen. During the next three years it became more obvious, and still more so by the age of 13 when he was last seen.

Case 2, aged 7. There was thought to be some increased arterial pulsation in the scapular regions when he was first seen, but it was indecisive. A year later it had increased and during the next three years it became more easily seen and more widely developed, and possibly again during the following three years, up to 14 years of age. Two years later it was not so easily seen, but this was due to an increase of weight and subcutaneous fat since he had been evacuated to the country. By 1947, when he was 21 , it was easily seen both at the front and back of the chest and also on the upper abdomen above the umbilicus, and had increased in the last 4 years.

Case 3, aged 25. No diagnosis was made at 25 , but at 28 years there was an obvious collateral circulation over the abdomen and round the scapulæ. She was not seen again for 10 years and it was then extremely obvious in all these sites. It may be that the circulation was not looked for carefully enough when she was 25 but it certainly became more obvious between 28 and 39 years of age.

Case 4, aged 17. The collateral circulation was already well developed. She died later that year.

Case 5, aged 19. The collateral circulation was already easily seen and felt all over the back and up the abdominal wall where the arteries were unusually tortuous and pulsating. Ten years later, when he was 29 , additional vessels were seen along both borders of the sternum. He himself thought they had become more visible during these last 10 years and were especially evident when he became heated.

Case 6, aged 13. There were some enlarged arteries round the scapulæ, but they were not very obvious. When he was 22 , it had increased and was seen in front along the borders of the sternum. In addition, palpation revealed several vessels that were not visible.

In most of these cases the collateral circulation became more obvious between childhood and adult life and in Case 3, rather surprisingly, it seemed to have increased between 25 and 39 years of age. An increase in weight with subcutaneous fat was important in hiding the collateral circulation and this should be remembered. A hot day or a hot room helped in making it more obvious. 
Where the collateral circulation was not very obvious it seemed most likely to be found in the scapular regions. In three (Cases 4,11 , and 13) it was palpable only in the scapular region, and generally palpation was a more sensitive method of detection than observation. In Case 9 the only sign of it that was noted was the notching of the ribs, but we would emphasize that the special method for demonstrating its presence was not used and we have not been able to get in touch with him again.

\section{A New Sign of Coarctation of the Aorta}

When this paper had been nearly completed, one of us (S. S.) found that, by making the patient stoop or bend forward with the arms hanging by the side, collateral arteries under the skin of the back and sides of the thorax suddenly appeared where none were visible before.

In two patients (Cases 14 and 15) no collateral arteries were visible on ordinary inspection, but on making them stoop forward, they at once became very prominent, and the diagnosis of coarctation could thus be made on this sign alone (see Fig. 1).

So far the sign has been found in 7 of 8 cases tested and the others have not been available for re-examination. In Cases 2, 3, 5, 11, and 13, the collateral circulation could already be seen, sometimes easily, but it became more prominent on bending forward and became visible in fresh places where it had not been seen before (see Fig. 2).

After the sign had been found positive in three consecutive cases it was hoped that it might be of general application, but in Case 6, where the collateral circulation could already be seen, bending forward did not seem to increase it in any way.

Other changes of posture also caused the collateral arteries suddenly to appear or to increase their prominence, such as forward movements of the shoulders with the arms brought forward. Another good position is for the patient to lie prone on a couch with a cushion under his chest and the arms hanging down over the edge. But the optimum method is by stooping or bending forward with the arms hanging vertically.

The reason for the sudden appearance of these arteries with this change of posture was rather puzzling at first. After discussion with Professor Whillis of the Anatomy Department, Guy's Hospital, he suggested that these particular movements simply widened the costoclavicular space. It follows that in cases of coarctation where this sign is positive, there must in ordinary positions be a sufficiently narrow space between the clavicle and the first rib to produce some constriction and obstruction of the subclavian artery. Any movement that increases the costo-clavicular space will then relieve this partial obstruction of the subclavian and so the vessels having their origin from the partially constricted artery will suddenly fill up and become larger so that collateral branches previously invisible will become easily seen. Stretching of the skin or gravity or compression of the abdominal aorta do not cause the arteries to show up in this way.

In coarctation of the aorta the subclavian artery is very often dilated and tortuous and so it is quite understandable that some partial compression would occur in the costo-clavicular space. In the cases that do not show this sign the space between the clavicle and the first rib is wide enough not to compress even the dilated subclavian artery. We do not think that compression by the other structures in the costo-clavicular space, such as the nerve plexus or the scalenus muscles, plays any important part.

We have tried to get X-ray evidence for the widening of this space. It has been difficult to find a position where one can take X-ray pictures that will show the amount of widening of the space with the forward position of the shoulders, but we think that in one or two cases stereoscopic views have demonstrated this.

Further evidence that the subclavian artery is partially compressed in the costo-clavicular space is provided by the increase of the radial pulse that follows forward movement of the shoulder or other movements that cause widening of the space. 
It is therefore advisable that in every suspected case of coarctation of the aorta, and even in many cases of high blood pressure, this sign should be looked for. The best position is with the patient stooping forward and with the arms hanging down vertically, and the back should then be examined in a good light. By this means we feel that fewer cases of coarctation will escape diagnosis.

\section{Notching OF THE RIBS}

Notching or scalloping of the ribs is almost pathognomonic of coarctation of the aorta though we have seen one suggestive case lately where the diagnosis seems excluded. It was present in every one of our cases examined radiologically though the degree varied considerably. In children it often has to be carefully looked for, as carefully as the collateral circulation, and in younger children it may be absent. Before 1946 we regarded it as perhaps the most decisive point in diagnosis, but increasing experience of feeling the femoral pulse makes us rank this as a more important sign because it can be found on clinical examination and because in children it is present from an earlier age.

Fray (1930) in a note added to his paper says that in one of King's cases there was no visible rib-notching in two films taken when the patient was 10 and 12, but that it had started to show when he was 17 years of age. Brown (1939) states that the youngest recorded example of rib-notching was at 6 years of age. Reifenstein, Levine, and Gross (1947) in a paper dealing mainly with cases that had come to autopsy quote a case of Farris (1935) where there was slight rib-notching in a boy of 11 years, and add that Bland and also Sosman had informed them of cases where they had seen it rather earlier than this. They found it present in 75 per cent of the 43 cases where the information was provided, but in adult cases diagnosed clinically it seems to be present more often than this.

In our Case 1 who was 7 when first seen it was slight but definite. In our Case 2 who was also 7, it was suspected but indefinite; one year later (1934) it could be clearly seen but was still slight (see Fig. 3 and 4). In the case of Rooke (1938), aged 3, there was no visible ribnotching although the collateral circulation was fairly well developed. Neuhauser (1946) has mentioned a case where it was said to be visible in an infant 9 months old, but the next youngest case referred to was 8 years old.

Notching of the ribs obviously depends on the degree of dilatation and tortuosity of the intercostal arteries in their contact with the ribs. In all the 5 patients observed over a period of several years the degree of rib-notching increased. Sometimes the increase is only in the depth of the notching, but sometimes especially in the younger patients the number of ribs affected also increased considerably. The changes were greater in some than in others.

Case 1, aged 7. Notching was slight but noticeable, at first in only 3 or 4 ribs. It had increased by the time he was 9 , and again when he was 11 years old. When last seen, aged 13, it was still only moderate (see Fig. 3).

Case 2, aged 7. Notching was suspected on careful searching, but was regarded as indecisive when he was first seen, though looking back at the film and comparing it with later ones it can be seen. A year later it was still slight in degree but was now decisive (see Fig. 4B), and after another three years there appeared to be a further increase. When he was 20 , there seemed to have been a further increase from the age of 11 , so that in this case the gradual erosion seems to have taken place over a period of many years (see Fig. 4). The number of ribs affected had also increased from 2 or 3 on one side in 1933 to 8 on both sides in 1947.

Case 3 , aged 25. The diagnosis was not made till she was 28 , though the high blood pressure had been noted at 25 . At 28 , a suggestion of rib notching was reported, but unfortunately the X-ray film has been lost. Eleven years later, when she was 39, it was well marked in the first 3 ribs on both sides. Here the rib notching and the collateral circulation both seemed to have continued increasing till a later age after the blood pressure had become stabilized.

Case 5, aged 19. This patient showed the least change, but all signs were well developed when he was first seen at the age of 19. Ten years later the notching was a little deeper in one rib and more clear-cut in another (see Fig. 8). 


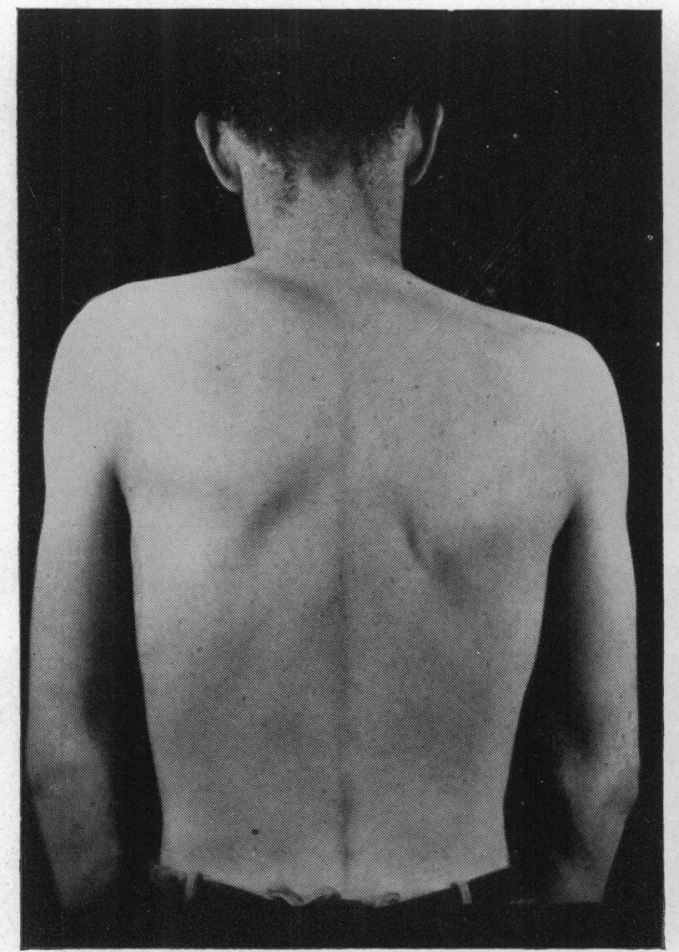

A

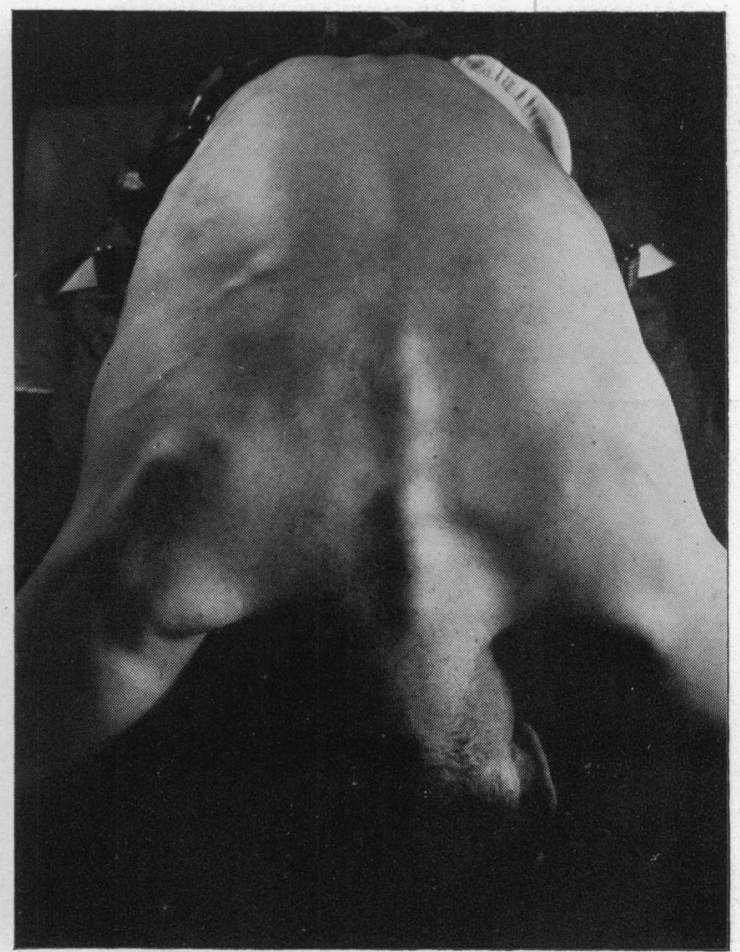

B

Fig. 1.-The collateral circulation demonstrated by bending forward, in Case 15. The picture in Case 14 was similar. (A) When standing upright, no collateral circulation could be seen even in a good light.

(B) After bending forward the collateral circulation can easily be seen and there is one specially obvious artery on the right. 

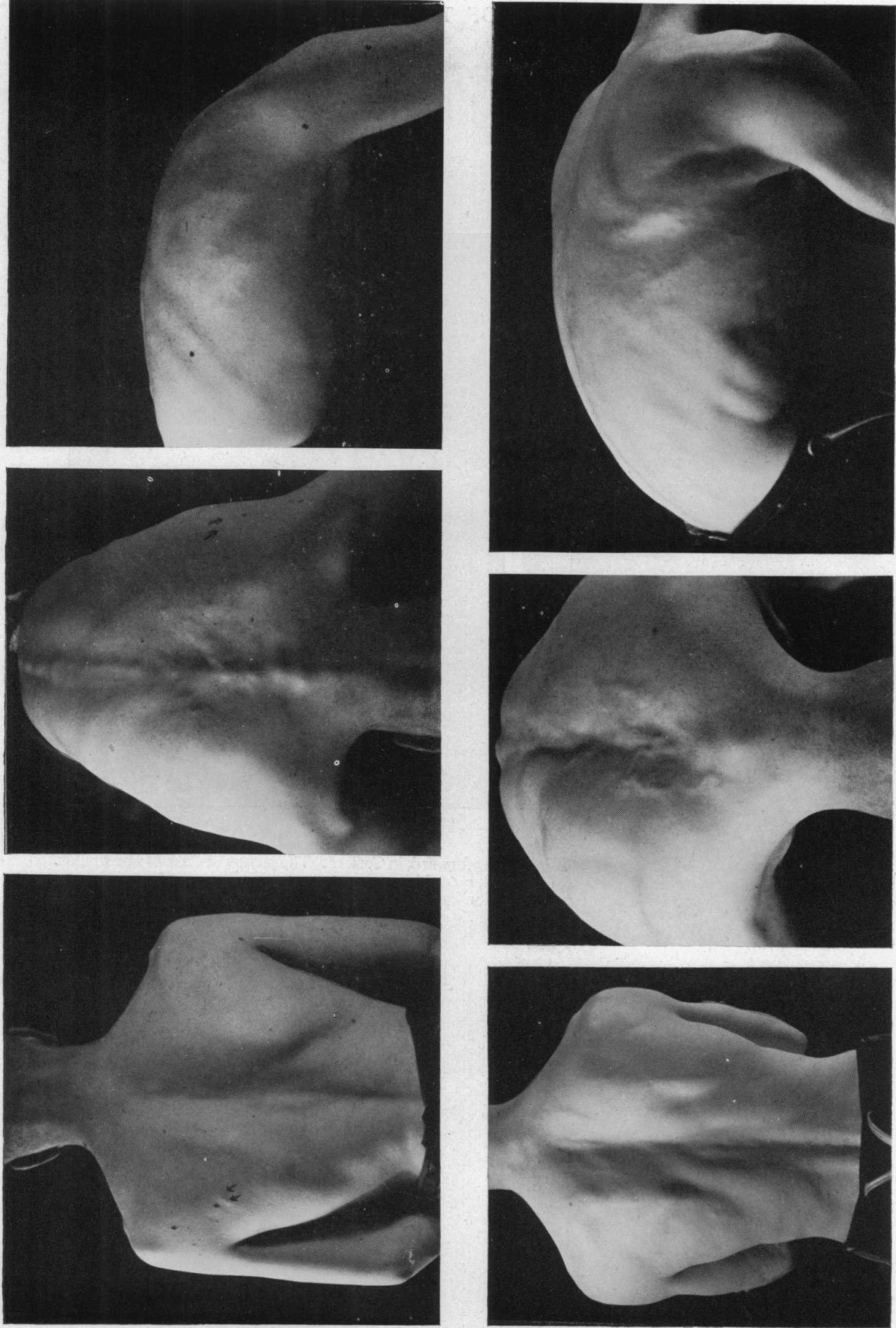

ฐై 뜸

预

ठํ워

递

늉요 $\overrightarrow{\overrightarrow{0}}$

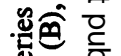

흔

उ के

$\approx$.

$\pi$ क क

兽五 $\overrightarrow{0}$

U 豕宁

की

费 范

焉

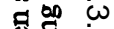

跘

唃 의

¿ण्]

产. 产

芯芯

证

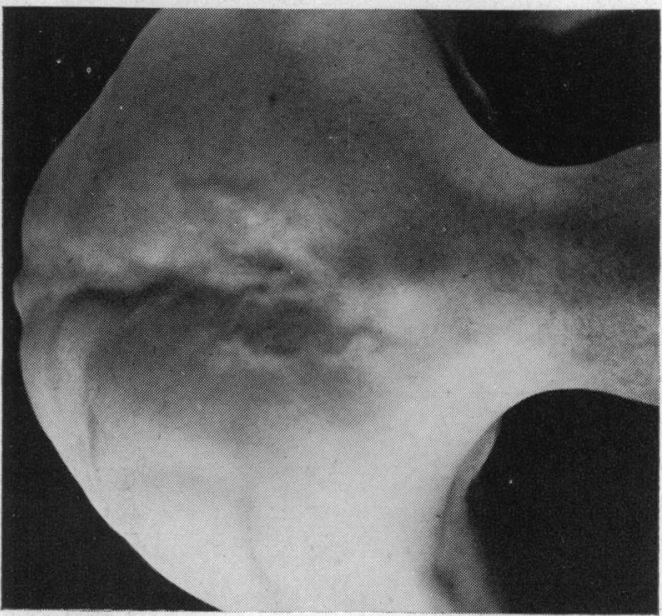

을

.

马्व

․․

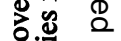



N量 3

岁券

$\infty$

.

定

政

है

을 을

이

当ㅇํㅇ

중

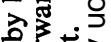

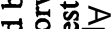

造

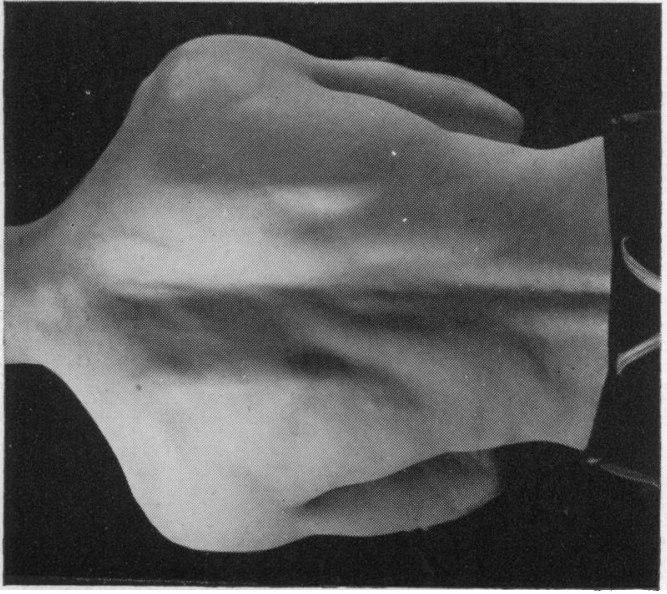

․․ำ

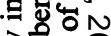

궁 ॠ 的《 울 ิํำ

ํํำ

$<$ 롤

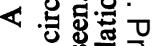

중

응

프유

8 동

․ㅜㅇㅝ

혁융

1 릉응

․ㅡㅇ

皅 产 

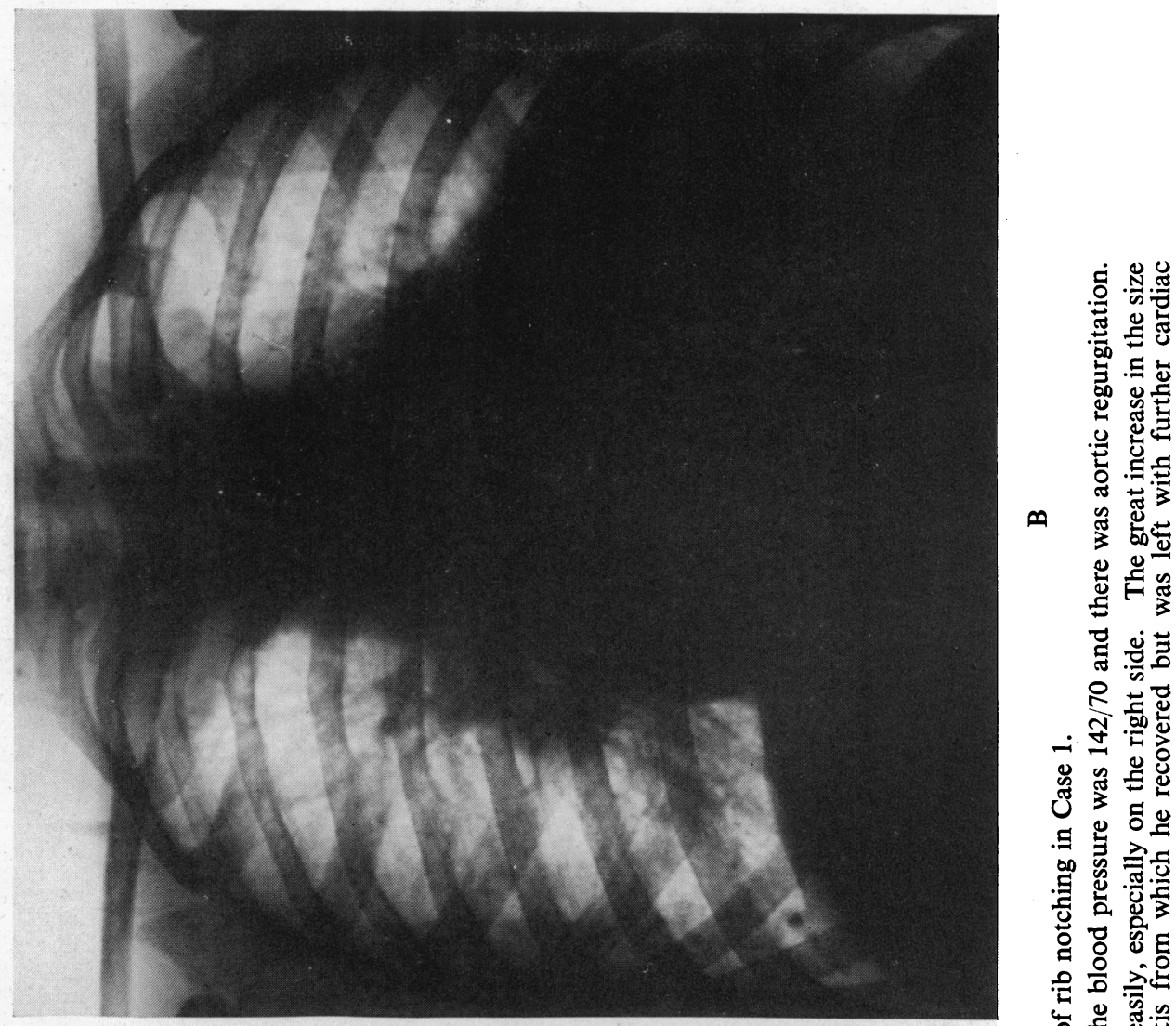

$\infty$

उ

氖

芯

오류

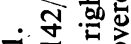

谞

ㅇํำ

들

㩆

氙

용

운 충

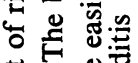

苋 흉

हो

을 릉

एँ

ช 웜

突薷苋焉

लं 空象它

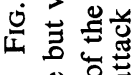

Q

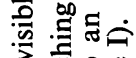

원융

党

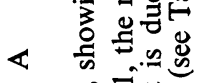

든

రृ

范

卷范范

ङิ 


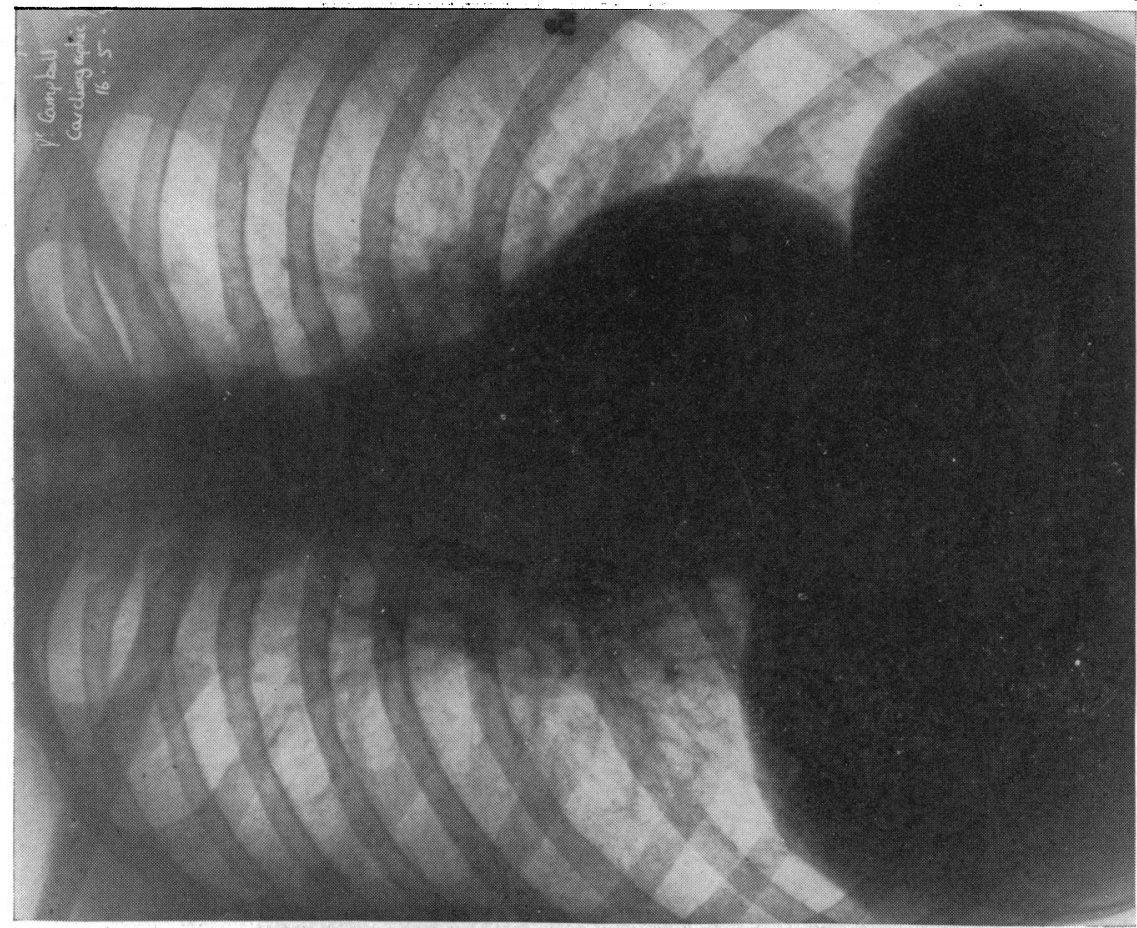

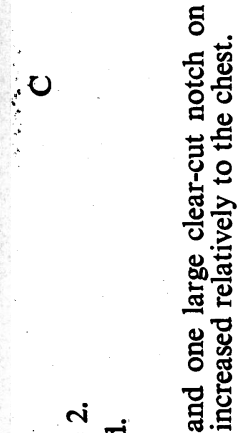

边芯

0

.

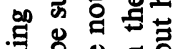

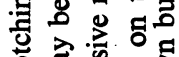

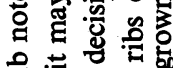

을. 웜

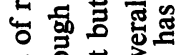

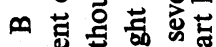

oी

응

궁

ఫे 형

\& क के 잉

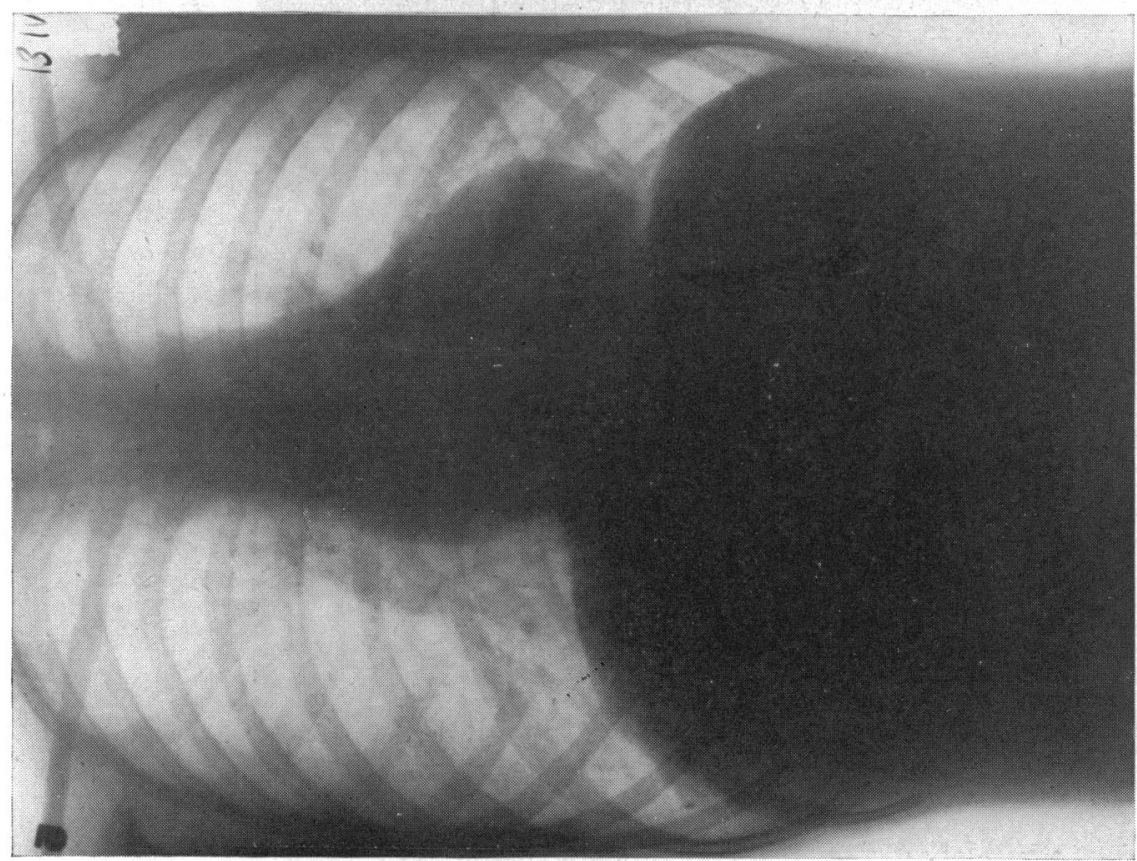

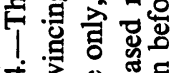

+ 宛

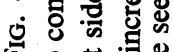

4. 궁

on

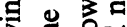

홍 웅흑

की

ป⿱一兀)

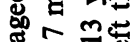

< 焉密焉

ษิ์ 

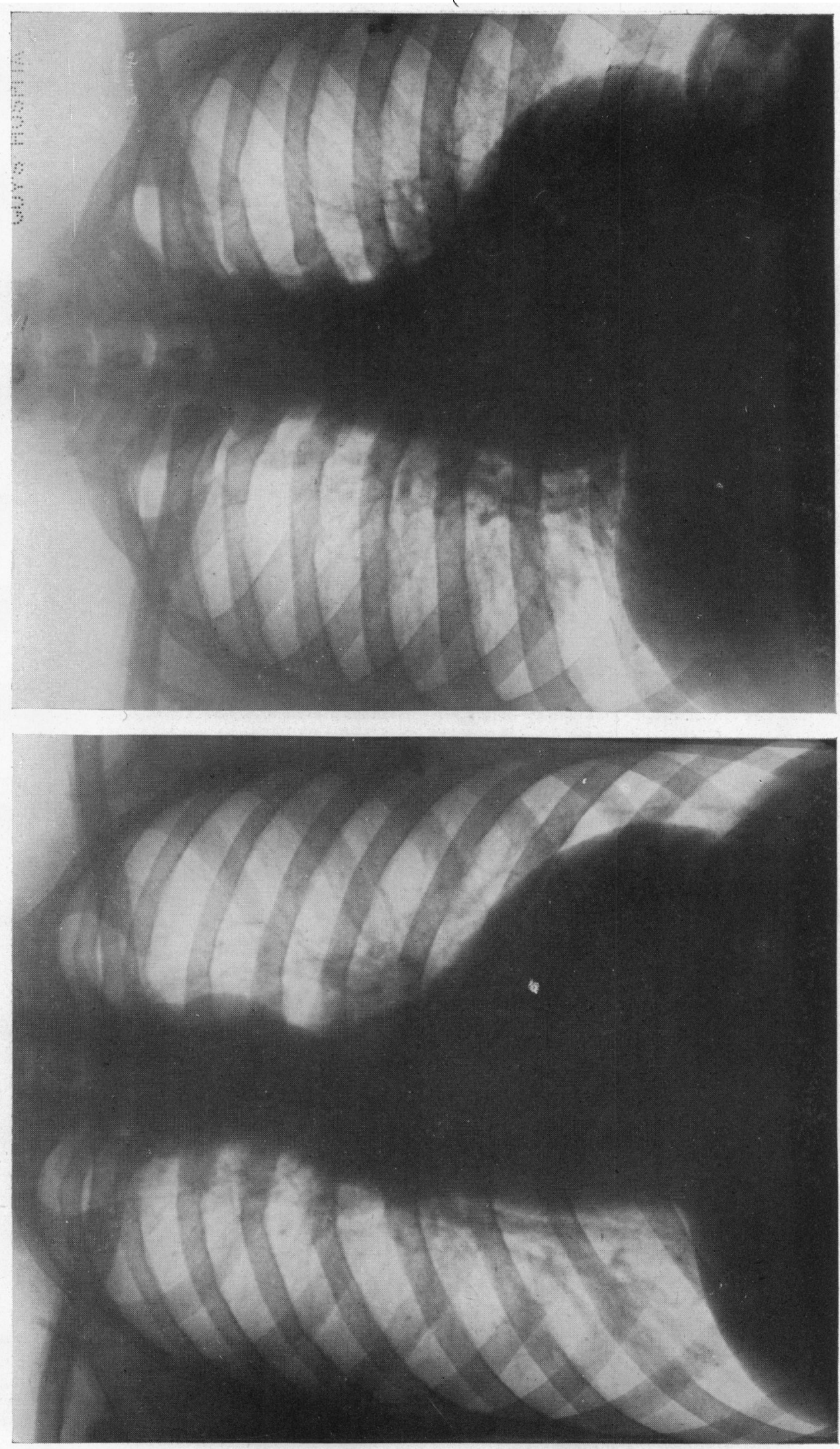

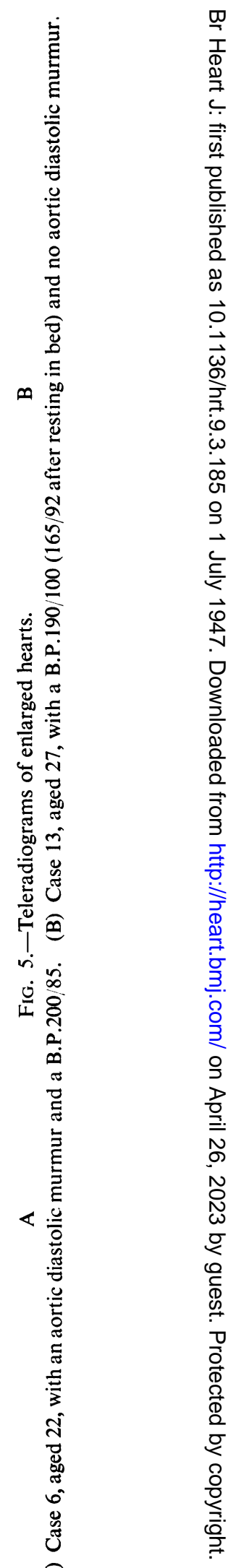



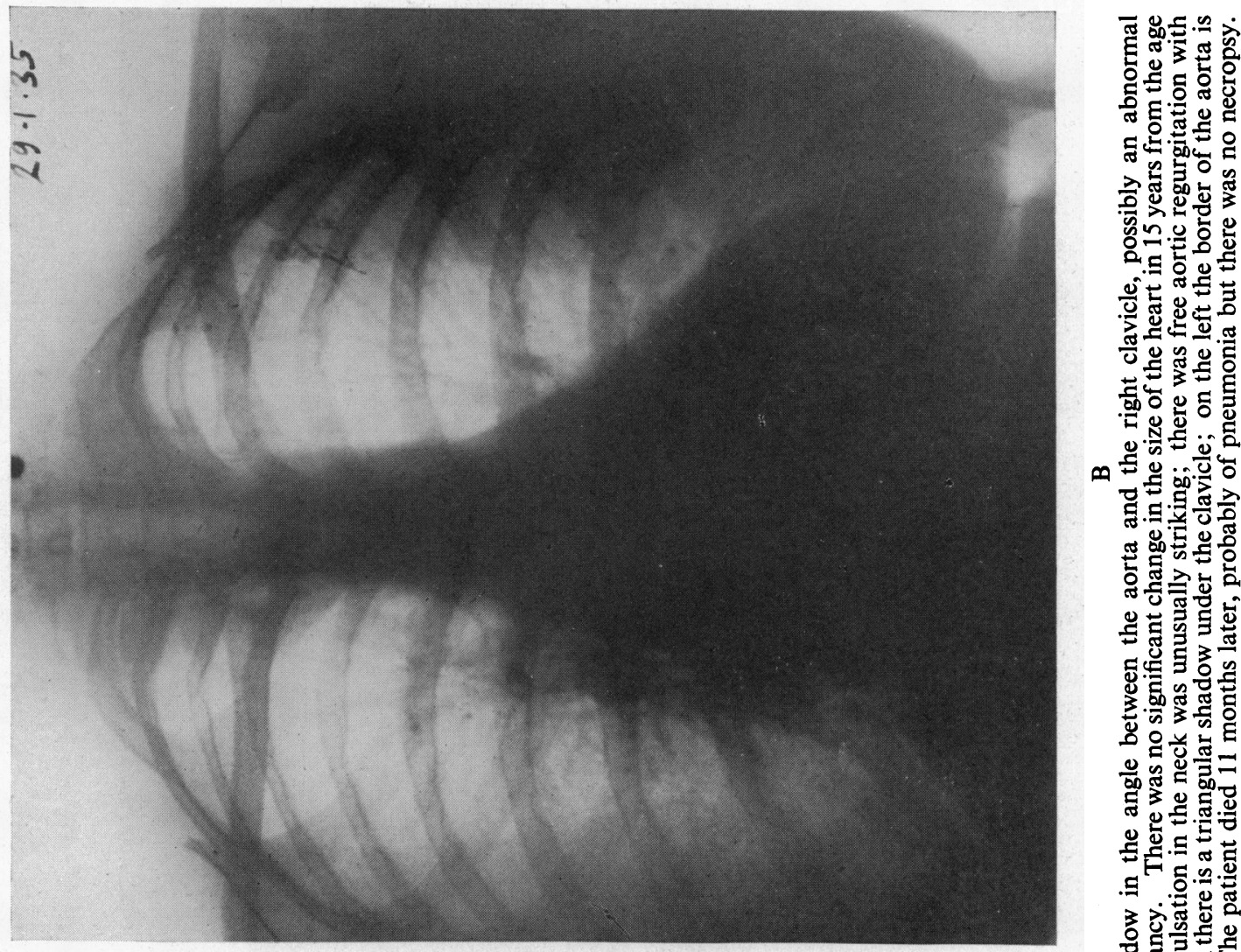

총ㅎㅇ원

त

ब

경

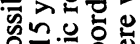

늠원

可

政四

웡

댕

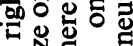

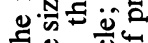

$\infty \neq 0$

를

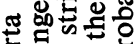

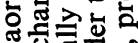

证要

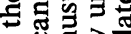

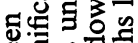

\&.

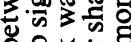

8 은

늘

포를.

政

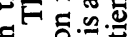

궁

3 定要

政

额

๙

उ단혈

的击恕

至才゙す

두은

路

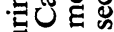

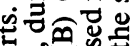

ฐ్ల జ

च응

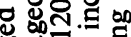

on $\pi$.

สำ유

दิ

正话

50

通究

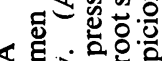

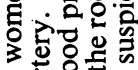

원응 ๘

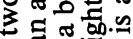

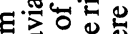

추원

연드의

的颔

ह

可

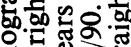

$7 \%$

풍주

엉이

战证

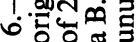

它 

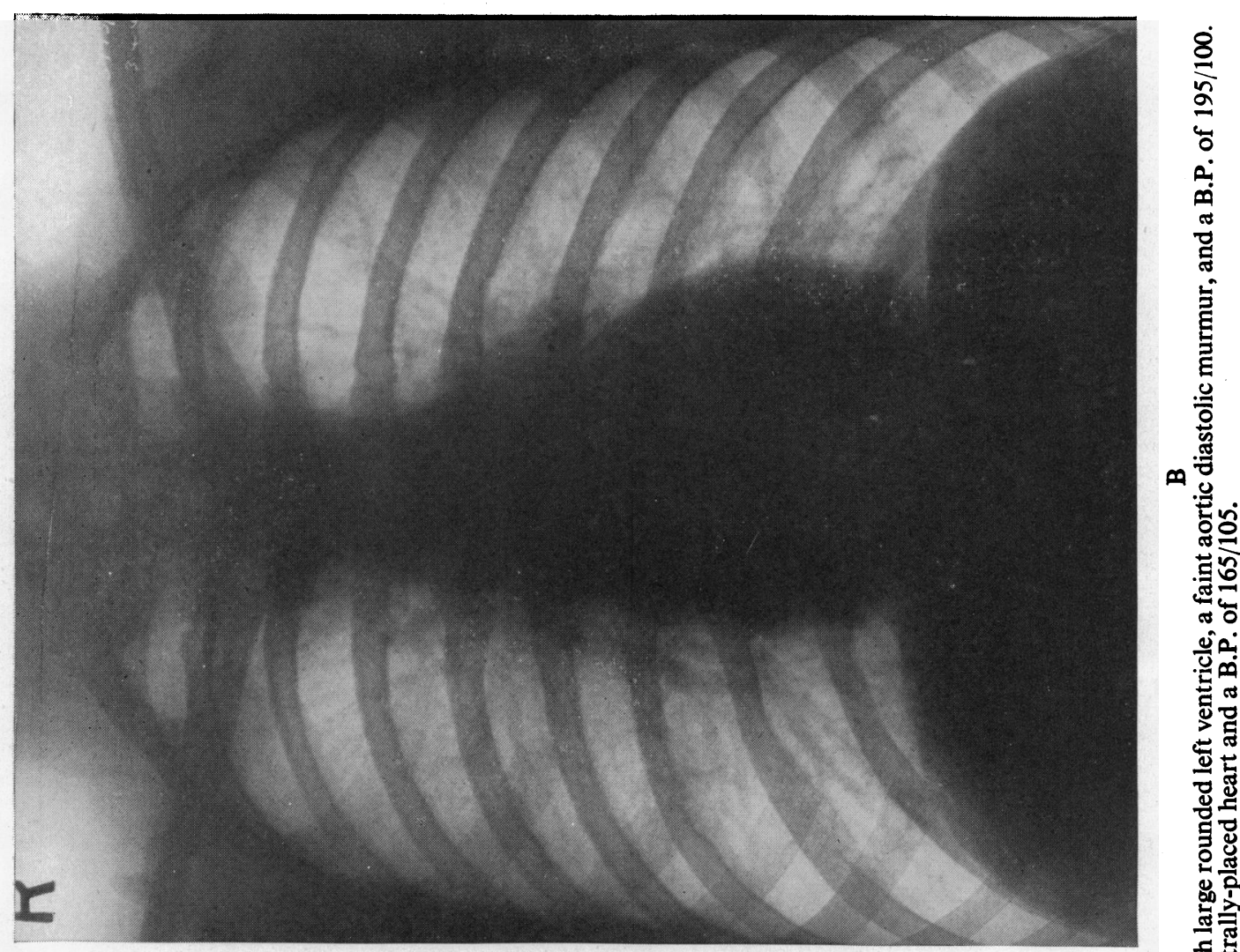

ํํㅇำ

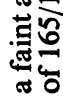

:

풍

จ물

돈

हुछ

要

훙

흘

芠苛

กิ

己ृ

章

$=$

总

它

a

象营

幽

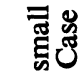

« 를

品

总

营

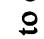

్ㅡㄹ

ํㅐㅇ

:

๘

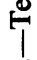

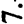

$\dot{0}$

$\underline{\square}$ 




.

놇 F 하틍 ำกำ $>$ 安 范 on. F跑 융 苞官 急 .

m 홍 to

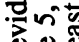
o.

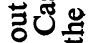
要公范 \% क⿺辶 ส] Eः 웡 4.9 .9 蝊运 3 논 胥 00 . 윤뎌 둑을 ฐ용 도영 혼를 뉴 วึํํㄱ 으렇 늘 西 造 훙응 등. 氙这 $<\pi$ 후으 ชั c. 운 告 政 응.형.으 臣的 ¿ 
- Case 6, aged 13. Although the blood pressure was already high and did not increase further, rib notching was only slight when he was first seen, the sixth left rib showing suggestive notching. Ten years later, when he was seen again, there were many areas in several ribs on both sides showing obvious shallow notchings (see Fig. 5A).

Dr. W. St. C. Symmers has given us details of a case he saw where the notching of the ribs. was not present' in a routine X-ray taken when he was 16 (1929) but was obvious when he was 30 years of age (1943). He had no symptoms, but at a routine examination in the Navy he had forcible pulsation in the arteries of the neck, some enlargement of the heart, systolic and diastolic murmurs widely conducted from the base, and a blood pressure of 195/95 (right arm), $185 / 95$ (left arm), and 105/75 in the leg. No pulse could be detected in either femoral artery. The X-ray of 14 years before was obtained and no notching or enlargement of the heart could be seen. In 1940 he had been examined by the Naval Mass Radiography Unit without comment, and the radiologist who re-examined it in the light of the subsequent findings said that it showed no abnormality.

Thus in all the cases followed for some years from childhood or early adult life, there was an increase in the depth of the notching or in the number of ribs affected or in both, though no doubt a stage is reached-later than the stabilization of blood pressure or even the development of the collateral circulation-when there is no further increase in the erosion of the ribs.

There seemed to be no correlation with the blood pressure, the murmurs, or the size of the heart, and only a limited correlation with the extent of the superficial collateral circulation, the notching of the ribs continuing to increase to a later age. Other points, especially the site and distribution of the notches and the mechanism of their production have been dealt with by Bramwell and Jones (1941): they state that it does not occur on the second rib but we think we have seen it there once, perhaps due to an abnormal artery (see Fig. 6).

\section{The SIze OF THE HeART}

Lewis (1933) pointed out that there might be no progressive enlargement of the heart over many years and stated: "C Cases do occur and are not infrequent in which with very high blood pressure the heart presents no sign of enlargement clinically even when examined by means of X-rays. It is improbable, however, that increased weight of the heart can be excluded by these means." And, in fact, Peacock (1860) found the heart generally enlarged in 18 of 40 cases, while in 10 others there was a moderate increase affecting chiefly the left ventricle, and Abbott (1928) found some enlargement in 154 of 200 cases where there was necropsy evidence.

It is clear, however, that high blood pressure in coarctation of the aorta does not produce as much enlargement as might be expected. Judged by the cardio-thoracic ratio many cases would be said to have no enlargement; but some degree of hypertrophy of the left ventricle seems usual though not constant as judged by the rounded contour of the left border of the heart (see Fig. 4, 5, and 7). Where there is much enlargement additional causes should be suspected, such as associated congenital defects, the development of aortic regurgitation often on the top of congenital bicuspid aortic valves, or secondary changes in the heart muscle, which in the cases of pure high blood pressure without the associated factors of ordinary hypertension may be delayed for very many years.

Of our 15 cases, 8 showed no enlargement or only a little enlargement of the left ventricle, as shown by some rounding of the left border, and 7 showed this in a more developed form so that there was some general increase. The maximum transverse diameter and the size of the chest for all our cases are given in Tables I and II.

Of the 7 with enlarged hearts, 4 had an aortic diastolic murmur (Cases 1, 4, 6, and 11) so that no doubt this was partly responsible for the increase in size. In the remaining 3 (Cases 3, 7, and 13) aged 25 to 36 years the blood pressure averaged 215/112 (230/120, 250/120, 
and $165 / 92$ respectively). In the four with diastolic murmurs the readings were $155 / 68$, $200 / 90,205 / 85$, and $195 / 100$ respectively (average $189 / 86$, or $200 / 92$ excluding the child).

There are considerable differences in the shape of the heart in coarctation, the only common feature being the left ventricular enlargement present in many cases. The differences in the shadow of the aortic pedicle are even greater and for this reason we have reproduced several films to illustrate different types.

The absence of the aortic knuckle in the radiogram has been emphasized as another classical sign of coarctation. This with a straight left border is well shown in Fig. 3A, 5B, and 6B. In other cases, as Bramwell (1947) has pointed out, there is a striking double curve the upper generally representing the tortuous and dilated subclavian artery and the lower the blind end of the descending aorta (see Fig. 7A and 8). In the paper by Hamilton and Abbott (1928) there are on successive pages a radiogram and a photograph of the specimen post-mortem and the correspondence of the upper curve with the subclavian artery is well shown. Fig. 5A is unusual in looking more like a case of aortic incompetence (which it was) with an apparent aortic knuckle.

In some cases there are unusual shadows on the right; in the angle of the clavicle and aorta, possibly an abnormal right subclavian artery (Fig. 6), and lower down on the right (Fig. 4A). The root shadows are often prominent and were specially so in Fig. 4C, 6B, and $7 \mathrm{~B}$.

Two men with enlargement of the heart, especially to the left, are shown in Fig. 5, and two women in Fig. 6; in each case one had and one had not got aortic regurgitation: possibly the shape of the aorta in Fig. 5A is suggestive of aortic regurgitation, but this is not true of Fig. 6B and otherwise the distinction could not be made on the X-ray film. In Fig. 7 another of the larger hearts is contrasted with a smaller one, both from young men of similar size and build.

Of the 8 with little or no enlargement, 4 showed no enlargement clinically or radiologically (Cases 5, 9, 14, and 15; see Fig. 7 and 8). The other 4 showed some rounding of the left ventricle only (Cases 2, 8, and 10; see Fig. 4) or slight enlargement clinically without an X-ray being available (Case 12).

The other 6 with no general enlargement were between 18 and 33 years of age and the blood pressure readings gave an average of 190/108 which is not much below the average figure $(215 / 112)$ for the three with moderate enlargement of the heart without an aortic diastolic murmur.

It is clear from these figures that in some cases, but not in all, the enlargement of the heart can be correlated to some extent with the presence of a diastolic murmur; but not, at any rate at all closely, with the level of the blood pressure, as this may be just as high in those with no enlargement.

Another point of interest is whether there is any progressive enlargement when the patients are followed for several years. In the younger patients because of the natural growth of the chest as a whole, absolute measurements are not enough and the cardio-thoracic ratio combined with inspection of the contour of the heart is probably the best guide.

In Case 1 the heart did increase in size over 6 years without much development of his chest, but he had aortic incompetence and an attack of rheumatic pericarditis (Fig. 3). In Cases 2 and 5 (Fig. 4 and 8) there was no progressive increase over 14 and 10 years.

The first (Case 2) in spite of a rising blood pressure (to 210/105) and the development of an aortic diastolic murmur still had a cardio-thoracic ratio well under $0 \cdot 5$, though there seemed a little rounding of the left ventricle. At 7 years the heart size was $9 / 19 \mathrm{~cm}$. with a blood pressure of $147 / 85$ : at 21 years it was $12 \cdot 5 / 29 \mathrm{~cm}$. with a blood pressure of $210 / 105$, so that the general growth of the chest was greater than the increase in the size of the heart (see Fig. 4). In the second (Case 5) there was not even a suspicion of rounding of the left ventricle and the 
cardio-thoracic ratio was $0.43(10.6 / 24.5$ when he was 19 and $11.2 / 26$ when he was 29), although the blood pressure had remained over 180/110 during these ten years (see Fig. 8).

In Case 3 there was possibly a slight increase during the period from 25 to 39 years of age, but it was hardly significant. In the last (Case 6) followed from 13 to 22 years of age it seemed that there was a slight relative increase from $(0.52$ to 0.56$)$ and that the heart was undergoing slight enlargement as well as natural growth.

On the whole there is no progressive increase in the size of the heart with the high blood pressures of coarctation unless complicating factors arise. No doubt a balance is reached with some increase in the left ventricle, and even this may be absent.

The relative absence of much enlargement is of theoretical interest also, because it is not found so often with other types of high blood pressure, presumably because in these cases the heart is also affected by the associated arterial disease, while in coarctation there is normal heart muscle to deal with the extra work. Graybiel, Allen, and White (1933) found no sclerosis of the arterioles or smallest arteries such as characterizes essential hypertension, and this probably applies to the coronary arteries also. These facts support the view that the importance of high blood pressure (and of valvular disease) in producing cardiac hypertrophy has been exaggerated: the size of the heart is also greatly influenced by whether the muscle is healthy or not and this helps to explain why the size of the heart is in most conditions of such great value in prognosis.

\section{Heart Murmurs}

The Systolic Murmur. Characteristically, this is loudest to the left of the sternum in the second and third intercostal spaces. It may or may not be widely transmitted, but is nearly always heard in the back towards the left side, a point that was recognized early (Fawcett, 1905). Sometimes there is a systolic thrill. In small children this systolic murmur may be the only physical sign noted and then other evidence of coarctation, especially the poor femoral pulse, should be searched for. When the collateral circulation is well-developed systolic murmurs may be heard very widely, but some of these may be produced in the tortuous and dilated arteries.

A systolic murmur was noted in all these patients when they were first seen, but the two youngest were already 7 and the next youngest was 13 years. In one (Case 13) the systolic murmur was rather faint and insignificant and in two others it became so-in one naturally. (Case 5) and in one after operation (Case 10).

Diastolic Murmurs. A diastolic murmur was heard at the base of the heart in 6 of our 15 patients: in one (Case 1) it may have been due to rheumatic aortic incompetence and in another (Case 2) without any obvious signs of infection it developed and gradually became more obvious, but without any fall in the diastolic pressure when he was between 10 and 14; in the other four it was noted when they were first seen at $13,17,17$, and 25 years of age respectively, and the readings of the blood pressure were 210/80, 200/90, 195/100, and 170/105 (average 194/94). Perlman (1944) reported it in 9 of 13 cases but this seems a higher proportion than usually.

A high diastolic pressure is the rule in coarctation, even in most cases when there is an aortic diastolic murmur. It is only when there is a greater degree of aortic incompetence caused by superadded changes in the valves that the diastolic pressure is low: these may be rheumatic or other inflammatory or atheromatous changes. Thus in Case 1, with rheumatic aortic incompetence the diastolic pressure was at first 60 and later $45 \mathrm{~mm}$. If the diastolic pressure is low infection of congenital bicuspid valves may often be suspected. Usually the diastolic pressure is relatively high even when there is a diastolic murmur. This probably means a slighter leak from atheromatous changes in bicuspid valves or perhaps even from some stretching of the aortic ring and it will be interesting to see if any of these diastolic murmurs disappear with surgical correction of the coarctation. 


\section{THE ELECTROCARDIOGRAM}

Lewis (1933) stated that there was generally left-sided preponderance: 6 of his 8 cases showed it but 5 of them were over 40 and the 2 who did not were younger-24 and 37 years of age. Brown (1939) considers there are no characteristic changes and that.normal axis deviation is often present though left axis deviation generally develops.

Of our 13 patients with cardiograms Case 1 developed left from some right axis deviation in the six years of observation, but as this and the increase in size of his heart may have been the effect of his increasing rheumatic aortic incompetence it is hardly fair to include him. Only 3 of the other 12 had left axis deviation-Cases 3 (25-37), Case 4 (17), and Case 7 (36)-the figures in brackets giving the ages at the time they were under observation. One, Case 2 (7-20), had well-marked right axis deviation. The remaining 8 had no axis deviation but it is of course possible they may develop it as they are all under 33 years of age.

It is, however, obvious from these figures that the electrocardiogram is of no value for diagnosis, as normal is more common than left axis deviation. The rounded left ventricle in radioscopy gives a better indication of the extra work put on the left ventricle, even when there is not enough enlargement to make the total measurements outside the normal range. The cardiogram is, of course, of interest and may be helpful in deciding on the presence of other abnormalities.

Other changes in our cases were T I, T II, and T III invęrsion (Cases 6 and 7), T 1 inversion (Cases 1 and 4), a biphasic T I (Case 14), slight widening and notching of QRS (Cases 2 and 15), Q III (Cases 12 and 13), an inverted P III (Cases 7 and 10), a biphasic P III (Case 14), and a prolonged P-R of 0.19 sec. (Case 10), of 0.20 sec. (Case 14), and of 0.22 sec. (Case 12).

\section{The Blood Pressure}

All writers agree that, with rare exceptions, the blood pressure in the upper part of the body is raised. Lewis (1933) found high blood pressure present in all his adult cases, and that in general it had no further tendency to rise and only fell terminally or with congestive failure. Often the symptoms seem very slight compared with what might be expected for the degree of hypertension, even where the rise of pressure is known to have been present for years. Our findings are given in Tables I and II. In general we have found the pressure rather variable from visit to visit and we, therefore, attach more significance to average figures, some representing a large number of readings taken over a period. Reifenstein et al. (1947) have also commented on the variability and quote a case where reading of $122 / 80$ and 180/85 were recorded. King (1937) quotes some similar cases-238/128 to 178/90 (Flexner), 210/170 to 160/90 eighteen months later (Lichtenberg et al.) - but.such cases are, of course, quite exceptional. We think the difficulty of measuring the blood pressure in the legs has not been stressed sufficiently. We have found no constancy as to whether it is easier by auscultation over the popliteal or by palpation of the posterior tibial or dorsalis pedis; we have often failed to get a convincing reading, though perhaps later in the same patient it has not been difficult to get a decisive level.

The average figure in our patients was 203/105 in the right arm, though in many we obtained one or more readings about $20 \mathrm{~mm}$. higher than this, and 130/85 in the leg; there were some where we could get no convincing reading of the diastolic pressure in the leg. These figures are very close to those of Lewis (1933)-207/105 in the arm and 116/- in the leg.

Rarely the pressure is much lower in the left arm because the left subclavian has its origin below the coarctation (Bayley and Holoubek, 1940). We have not encountered an example of this but have found three cases where many readings gave a persistent difference presumably due to tortuosity of the arteries or unnatural angles of flow of the blood stream. Reifenstein et al. (1947) attribute this difference which was present in many of the cases collected by King (1937) to pressure of the distorted aorta above the coarctation on the left subclavian. 
In our Case 3 the figures were 235/118 in the right arm and 220/112 in the left; in Case 13, $165 / 92$ in the right, and 155/92 in the left; and in Case 5, 180/107 in the right and 167/102 in the left, and ten years later 186/120 and 175/110 respectively. All these figures were the average of a large number of readings often by various observers.

TABLE I

Blood Pressure and Size of the Heart in Cases of Coarctation Observed over some Years

\begin{tabular}{|c|c|c|c|c|c|c|}
\hline \multirow{2}{*}{$\begin{array}{l}\text { Case No. } \\
\text { and Sex }\end{array}$} & \multirow{2}{*}{$\begin{array}{c}\text { Age } \\
\text { (in years) }\end{array}$} & \multicolumn{2}{|c|}{ Blood Pressure } & \multicolumn{3}{|c|}{ Size of Heart } \\
\hline & & Rt. arm & Leg & m.t.d. (cm.) & Chest (cm.) & C-T ratio \\
\hline $\begin{array}{c}1 * \\
\text { Male }\end{array}$ & $\begin{array}{r}7 \\
10 \\
12 \\
13\end{array}$ & $\begin{array}{l}142 / 70 \\
155 / 70 \\
157 / 72 \\
165 / 60\end{array}$ & $\begin{array}{c}100 / 50 \\
95 / 60 \\
\overline{1} /-\end{array}$ & $\begin{array}{r}11 \cdot 5 \\
13.5 \\
(17.0 \\
15.0\end{array}$ & $\begin{array}{l}21 \\
21 \\
21 \cdot 5) \dagger \\
22\end{array}$ & $\begin{array}{l}54 \\
64 \\
68\end{array}$ \\
\hline$\stackrel{2}{\text { Male }}$ & $\begin{array}{l}7 \\
9 \\
11 \\
14 \\
16 \\
21^{*}\end{array}$ & $\begin{array}{l}147 / 85 \\
159 / 88 \\
176 / 95 \\
180 / 100 \\
210 / 110 \\
210 / 110\end{array}$ & $\begin{array}{l}110 / 60 \\
125 /-\end{array}$ & $\begin{array}{r}9 \cdot 2 \\
10 \cdot 0 \\
10 \cdot 0 \\
11.0 \\
\overline{12.5}\end{array}$ & $\begin{array}{l}19 \\
20 \\
21 \\
24 \\
29\end{array}$ & $\begin{array}{l}48 \\
50 \\
48 \\
46 \\
43\end{array}$ \\
\hline $\begin{array}{c}3 \\
\text { Female }\end{array}$ & $\begin{array}{l}25 \\
28 \\
38 \\
40\end{array}$ & $\begin{array}{l}230 / 120 \\
210 / 110 \\
230 / 120 \\
240 / 120\end{array}$ & $120 / 85$ & $\begin{array}{l}14 \cdot 0 \\
13 \cdot 5 \\
15 \cdot 5 \ddagger \\
14 \cdot 5\end{array}$ & $\begin{array}{l}\overline{25} \\
27 \cdot 5 \ddagger \\
25 \cdot 5\end{array}$ & $\begin{array}{l}\overline{54} \\
56 \\
57\end{array}$ \\
\hline $\begin{array}{c}5 \\
\text { Male }\end{array}$ & $\begin{array}{l}19 \\
29\end{array}$ & $\begin{array}{l}180 / 107 \\
185 / 120\end{array}$ & $115 /-$ & $\begin{array}{l}10 \cdot 5 \\
11 \cdot 2\end{array}$ & $\begin{array}{l}24 \cdot 5 \\
26 \cdot 0\end{array}$ & $\begin{array}{l}43 \\
43\end{array}$ \\
\hline $\begin{array}{c}6^{*} \\
\text { Male }\end{array}$ & $\begin{array}{l}13 \\
22\end{array}$ & $\begin{array}{l}210 / 80 \\
200 / 85\end{array}$ & $\begin{array}{l}115 / 90 \\
125 /-\end{array}$ & $\begin{array}{l}13.0 \\
15.7\end{array}$ & $\begin{array}{l}25 \\
28\end{array}$ & $\begin{array}{l}52 \\
56\end{array}$ \\
\hline
\end{tabular}

* With an aortic diastolic murmur.

$\dagger$ During rheumatic pericarditis.

$¥$ During pregnancy.

TABLE II

Blood Pressure and Size of the Heart in Coarctation of the Aorta

\begin{tabular}{|c|c|c|c|c|c|c|}
\hline \multirow{2}{*}{ Case No. } & \multirow{2}{*}{ Sex and Age } & \multicolumn{2}{|c|}{ Blood Pressure } & \multicolumn{3}{|c|}{ Size of Heart } \\
\hline & & Rt. arm & Leg & m.t.d. (cm.) & chest $(\mathrm{cm})$. & C-T ratio \\
\hline $\begin{array}{l}4^{*} \\
7 \\
8 \\
9 \\
10 \\
11^{*} \\
12 \\
13 \\
14 \\
15^{*}\end{array}$ & $\begin{array}{l}\text { f. } 17 \\
\text { m. } 36 \\
\text { m. } 30 \\
\text { m. } 29 \\
\text { m. } 30 \\
\text { m. } 27 \\
\text { m. } 33 \\
\text { m. } 27 \\
\text { m. } 18 \\
\text { m. } 26\end{array}$ & $\begin{array}{l}200 / 90 \\
250 / 120 \\
190 / / \\
230 / 130 \\
190 / 110 \\
195 / 100 \\
195 / 90 \\
165 / 92 \\
165 / 105 \\
169 / 107\end{array}$ & $\begin{array}{l}140 / 90 \\
160 / 120 \\
120 /- \\
135 / ? 85 \\
120 / 80 \\
130 / 90 \\
140 /- \\
130 /- \\
110 / 90\end{array}$ & $\begin{array}{l}14 \cdot 5 \\
15.0 \\
\overline{13.0} \\
12.5 \\
14.0 \\
\overline{16 \cdot 3} \\
11.0 \\
13.5\end{array}$ & $\begin{array}{l}26 \\
28 \\
28 \\
28 \\
27 \\
\frac{31}{27 \cdot 5} \\
29\end{array}$ & $\begin{array}{l}56 \\
53 \\
46 \\
45 \\
52 \\
52 \\
40 \\
47\end{array}$ \\
\hline
\end{tabular}

* With an aortic diastolic murmur. 


\section{The Rise in Blood Pressure}

Cases of coarctation are rarely diagnosed clinically in infancy, and this is partly because the pressure does not rise greatly for some years.

Lewis (1933) wrote: "It may seem natural to assume that if high pressure is found in the adult case, it has been present from the first year of life, but experience shows that such assumptions are not without danger: the conclusion that coarctation represents life-long high pressure becomes more and more justified as these pressures are recorded over longer periods. In this series there are records of high pressure extending over 5, 6, 6, 9, 13, 15, and 16 years. We still lack records covering childhood and adolescence."

Lewis (1933) collected the records of some reported cases with readings of the blood pressure, but only four of these were under 20 years. Since then Hunter (1928) has reported a boy of 14 with a pressure of 165/90, Hampson (1931) one of 12 with a pressure of 145/75, and Moncrieff (1931) a child of 6 with a pressure of 150/100. Wilkinson (1932) reported a child aged 4 with a pressure of $150 / 80$ in the arms, a feeble iliac pulse, but no obvious collateral circulation; another, aged 14, with a pressure of 198/135 in the arms, no palpable pulse in the leg, and a well-developed collateral circulation; Sheldon (1932) one, aged 12, with a pressure of 150/100, no palpable femoral pulse, and some collateral circulation; and Rooke (1938) a boy, aged 3, with an arm pressure of $150 / 85$, an absent femoral pulse, and a fairly well-developed collateral circulation but no visible notching of the ribs.

King (1937) made a very complete collection of all the reported cases with readings of the blood pressure and Steele (1941) continued this, both including some additional young cases.

We have found few records of the development of this high pressure, but in Case 2 of Farris (1935) it was $120 / 80$ when he was $9,142 / 70$ when he was $15,160 / 90$ at 17 , and 166-180/74-90 at 19 years. Schwartz and Tice (1939) describe a boy where it was said to be "normal" at 15, 180 at 18 when examined for life insurance, and 176/107 at 23 years. Steele (1941) reports a case where it was said to be " raised" at 10 , and was $220 / 110$ at 33 years.

Two of our cases illustrate this rise of pressure, one especially well as it was observed rising from 7 to 16 years of age when it began to stabilize; in a third case the maximum had certainly been reached by 13 and no change took place in the next 10 years. Of course the variation may be wider than this though we think it unlikely that there is any further rise of pressure after the period of growth is completed.

The two youngest cases in our series were 7 years old when the diagnosis was first made. In both these the pressure gradually increased. In Case 1 it averaged 142/70 in 1932-3, $155 / 70$ in $1935-6,157 / 72$ in 1937 , and $165 / 60$ in 1938 when he was 13 and was lost sight of: the low diastolic was no doubt due to aortic incompetence.

Case 2 was seen originally because of the blood pressure after scarlet fever, though investigations showed no renal changes. In 1933, when he was 7 , the pressure averaged $147 / 85$; in 1934-6 it averaged 159/88; in 1937, 176/95; and in 1938, 165/100; in 1940 a single reading was $180 / 100$; in 1942, 210/110; and 1946, when he was 20,210/105. In this case the pressure rose from $147 / 85$ when he was 7 to $210 / 110$ when he was 16 , and then began to stabilize.

None of the other cases were as young as these two when they first came under observation and the pressure already seemed to have risen to a level that has been maintained without much change. In Case 6 the blood pressure was already 210/80 when he was 13 and is 200/85 nine years later; in Case 4 it was 210/87 when she was 17 years old (she died later that year); and in Case 5 it was from 200/120 to 180/107 when he was 19 and 185/120 ten years later.

In the older patients we only have one with a long series of blood-pressure readings over many years; in her it showed no significant change from 25 to 40 years of age, being about $230 / 120$ when she was up and about and 190/100 to 205/110 when she had been resting.

These three cases with no great change in the pressure during ten years agree with Lewis's view that the blood pressure can remain at a steady high level for a great number of years till death or the onset of congestive failure. His cases were older than ours, the two youngest being 20 and 24 . 
Apart from these individual patients followed over some years we have approached the problem in another way. We have taken the average figure for the blood pressure for each age from all the cases mentioned here, from all tabulated by Lewis (1933), by King (1937), and by Steele (1941), and from our own cases. Where these have been followed for some years with frequent readings of the blood pressure they have been included once for each year of observation and a few other reported cases have been included more than once where the data were available.

With the relatively small numbers available (85 values between 3 and 19) and the great variation the average figures for each year are very erratic but there seems no doubt of their becoming gradually higher. To make the numbers in each group a little larger all cases up to 7 were combined, those aged 8 or 9 , those aged 10 or 11 , etc., and from these averages Fig. 9 has been constructed. It appears that there is a steady rise from 5 years to 16 or 18 years after which the rate of increase tends to be less steep. We have found no adequate data below the age of 5 years.

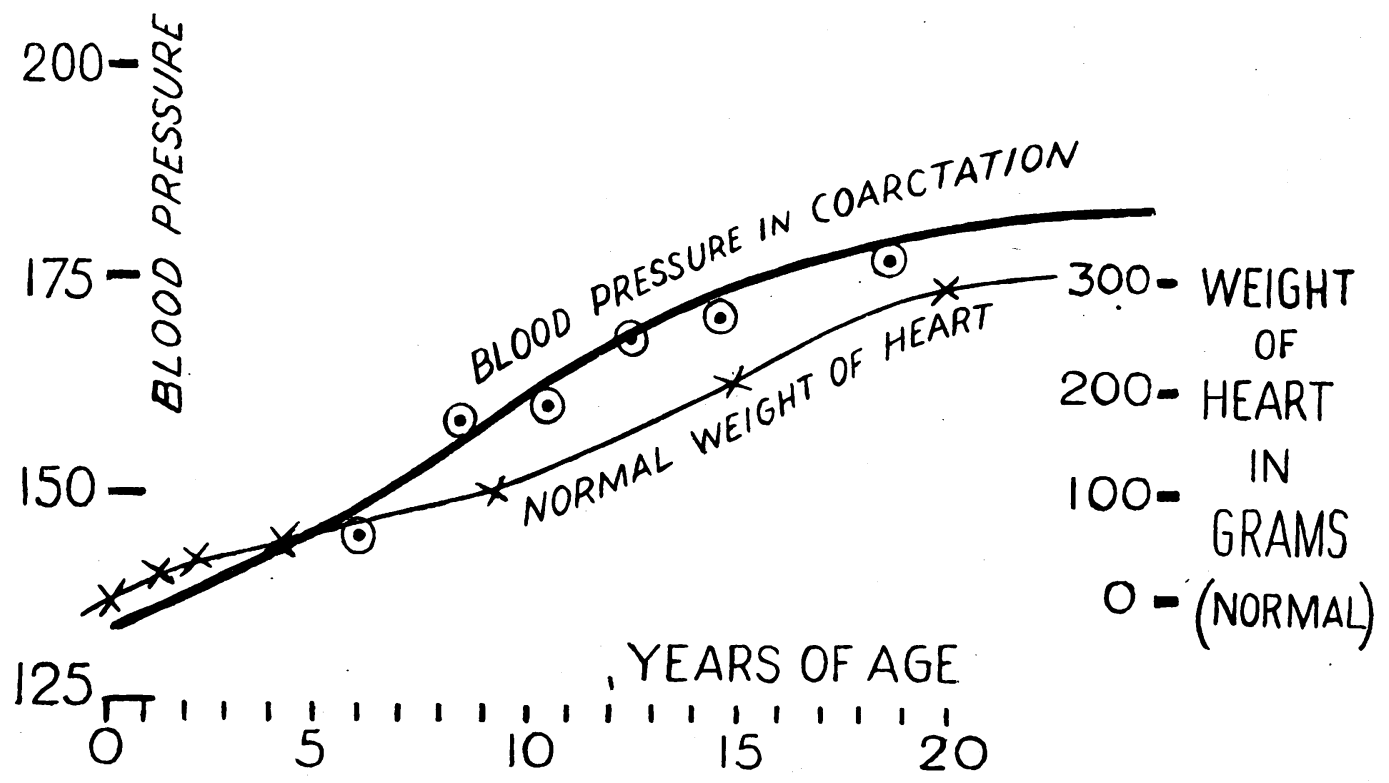

FIG. 9.-Diagram showing the average rise of systolic blood pressure with age in coarctation (see text) and for comparison the average increase of weight of the heart in normal children.

This fits in with the view that the blood pressure rises most quickly during the period of most rapid growth. The increase in the weight of the heart with age has been plotted on the same diagram from the figures given by White (1931). This probably gives a nearèr approach to the increase in size of the aorta than the increase of body weight as a whole would, partly because of their closer functional relationship and partly because the heart increases less with age than does the body weight, the heart being 1/130th of the body weight at birth and 1/200th of the body weight in adult life (Quain's Anatomy, Vol. II, Part 2, p. 374).

There is some general resemblance between the shape of these two curves, one for the rise of the blood pressure in coarctation and the other for the normal increase in the weight of the heart; and this supports the view that the rise of blood pressure during the period of most rapid growth is because the pathological stenosis of the aorta remains the same size, or does not increase at the same rate as the rest of the aorta. The consequence is that the obstruction 
to the circulation becomes greater with a resultant rise of blood pressure and a resultant increase in the collateral circulation.

Lewis (1933) suggested that it had not yet been proved that obstruction was the cause of the raised blood pressure and that such measurements as were available showed that the total area of the main arteries carrying the collateral circulation was much the same as the area of the aorta before the obstruction. If this is true it might be that in a slowly moving stream there would be no rise of pressure. In the arteries, however, the blood is moving with great speed and the pressure depends not only on the total calibre of the vessels but also on the resistance caused by contact with the vessel walls; and the more the main channel is divided into separate arteries and the longer the path, the greater will be the resistance from this point of view.

It seems natural to assume that the high blood pressure proximal to the obstruction is the result of this obstruction. Nevertheless, several writers have suggested since Goldblatt's work on renal hypertension, that this factor is also at work in coarctation. But if such a humoral mechanism were at work it should affect the legs as much as the arms, and the fact that it does not do so or does not do so to the same extent, brings one back to the obstruction as preventing the transmission of the high pressure from above it to the area below it. In so far as there is a tendency for the diastolic pressure in the legs to be high such a humoral mechanism might be responsible, but it seems more naturally related to the small pulse pressure in the legs. This is to be expected from the slow steady flow that takes place into the legs through longer and more devious channels and tends to damp down the usual pulse pressure.

Finally if operative removal of the obstruction is followed by a return of the blood pressure to normal as seems likely from the early reports (Crafoord and Nylin, 1945) this will support the view that the obstruction is the direct cause of the rise.

\section{Prognosis}

The possibility of surgical treatment of coarctation of the aorta has emphasized the need for a reasonably accurate prognosis. Fortunately there is evidence on which this can be based-more than we have in the case of patent ductus arteriosus, the relative lack of which have been pointed out by Gilchrist (1945).

The classic paper of Maud Abbott (1928) summarized what was known of 200 collected cases, all supported by the evidence of an autopsy. Of these, 70 per cent died between the ages of 10 and 40, and the deaths were almost equally distributed in these three decades, the mode being between 20 and 30 and the average age at death being just over 30 years.

The causes of death were cardiovascular in four-fifths and from other causes in one-fifth: in more detail, heart failure in 30 per cent; sudden cardiac deaths in under 10 per cent; ruptured aorta and related causes in 20 per cent; endarteritis in 7 per cent; and cerebral hæmorrhage, often from proved congenital aneurysms, in 13 per cent; these making 80 per cent of the total.

Special reported cases might not give a fair impression of the ordinary prognosis but there are two series detailing all those dying in hospital during a long period from 1826 to 1902 in Guy's Hospital (Fawcett, 1905) and from 1909 to 1932 in the London Hospital (Evans, 1933). They not only agree in placing the total incidence at about one case of coarctation in each 1000 necropsies, but also in the average age at death which was 31 in Fawcett's series and 29 years in Evans's series, excluding those of the " infantile" type with multiple congenital defects who died in the first few years of life.

Even these figures, being deaths in hospital, may be considered too pessimistic and it is, therefore, worth considering Bramwell's figures. The average age of his 10 patients who had died was 32 , but this figure will be considerably increased as the average age of the 13 patients who were alive was already 35 years. The age of death in Lewis's cases (1933, and Bramwell, 1947, Table X) were older, just over 50, but these were patients who had been fit enough to serve in the army during the war of 1914-18. Bramwell concludes " that patients whose 
symptoms date from childhood are unlikely to reach the age of 30 , whereas in those who are free from symptoms until the age of 30 , the further expectation of life is much more favourable."

As these older patients, free from symptoms up to 30 , are less likely to be thought suitable for operation, the other figures are all in rather close agreement that the prognosis of those with symptoms cannot be described as better than fair, with an expectation that on the average life is not likely to be prolonged much beyond 30 years.

It seems, therefore, that successful operative treatment has much to offer, provided the risk is not too great and that the fall of blood pressure found in the early cases proves to be general, as seems likely on theoretical grounds. But the risk of a fatal accident from other congenital abnormalities should not be forgotten, especially from rupture of a cerebral aneurysm, though the fall in blood pressure may, help in preventing this catastrophe.

\section{SUMMARY AND CONCLUSIONS}

Coarctation of the aorta still passes unrecognized. It will continue to be missed if a striking collateral circulation is always expected to be self-evident. It will be diagnosed if the femoral pulse is felt for and the blood pressure taken in the legs in every case with high blood pressure or with basal systolic or diastolic murmurs, or with undue pulsation in the neck, when these are without an obvious cause.

The collateral circulation can be demonstrated in many patients when it is not evident, or made more obvious in others, if the patient is made to stoop forward with his arms hanging down vertically while his back is examined in a good light. This is because the greatly dilated subclavian artery is compressed between the clavicle and the first rib: bending forward opens up the costoclavicular space and so releases this pressure on the subclavian artery. Any movement that increases the costoclavicular space may demonstrate this sign.

A high pressure in the arms with a low pressure and a poor femoral pulse, or the demonstration of a collateral circulation are pathognomonic of coarctation of the aorta. They are even more important than notching of the ribs, not only because X-rays are not always available, but because they are present at an earlier age.

The rise of blood pressure, the collateral circulation, and the notching of the ribs develop as a rule between the ages of 6 and 16, but more information is needed about cases at the younger ages. The blood pressure seems to stabilize first, at about 14 to 18 , the collateral circulation continues to develop rather longer, and the notching of the ribs still longer.

The rise of blood pressure and the increase in the collateral circulation occur during this period of rapid growth, we suggest, because the stenosis of the aorta does not increase in crosssection (or increases relatively little) with the growth of the rest of the aorta so that the relative obstruction becomes greater.

Average figures for the blood pressure are about 200/105 in the arm and 130/85 in the leg. Thus in the arm there is a greater rise of the systolic than of the diastolic blood pressure. In many cases with an aortic diastolic murmur the diastolic pressure remains fairly high. The relatively normal diastolic reading in the legs is against the view that there is a genuine hypertension following renal ischæmia.

More than half our cases had little or no clinical or radiological enlargement of the heart, though this cannot exclude some small increase of weight and the left ventricle was often rounded. Enlargement was more likely where there was an aortic diastolic murmur (6 of 15 cases) though even then it was sometimes slight. As Lewis found, the heart may not increase in size during many years' observation.

The electrocardiogram is of no value for diagnosis: left axis deviation was present in only a quarter of these patients, aged 7 to 39 years.

The average expectation of life of those with symptoms before adult life is probably no 
more than 30 years, so that cure by operation has something to offer. Where the diagnosis is made for the first time in adult life, and especially in those without symptoms, the outlook is relatively good.

\section{REFERENCES}

Abbott, M. E. (1927-8). Amer. Heart J., 3, 381, 392, and 574.

Blackford, L. M. (1926). Arch. intern. Med., 41, 702.

Bramwell, C. (1947). Brit. Heart J., 9, 100.

- , and Jones, A. M. (1941). Ibid., 3, 205.

Bayley, R. H., and Holoubek, J. E. (1940). Ibid., 2, 208.

Brown, J. W. (1939). Congenital Heart Disease, John Bale, London, pp. 53-65.

Crafoord, C., and Nylin, G. (1945). J. Thoracic Surg., 14, 347.

Evans, W. (1933). Quart. J. Med., 26, 1.

Farris, H. A. (1935). Canad. med. Ass. J., 32, 276.

Fawcett, J. (1905). Guy's Hospital Reports, 59, 1.

Fray, W. W. (1930). Amer. J. Roentgen., 24, 349.

Gilchrist, A. R. (1945). Brit. Heart J., 7, 1.

Graybiel, A., Allen, A. W., and White, P. D. (1933). J. clin. Invest., 14, 52.

Hamilton, W. F., and Abbott, M. E. (1927-8). Amer. Heart J., 3, 381.

Hampson, A. C. (1931). Proc. Roy. Soc. Med., 25, 420.

Hunter, D. (1928). Ibid., 21, 432.

King, J. T. (1926). Arch. intern. Med., 38, 69.

$$
\text { (1937). Ann. intern. Med., 10, } 1802 .
$$

Lewis, T. (1933). Heart, 16, 205.

Moncrieff, A. (1931). Proc. Roy. Soc. Med., 25, 720.

Neuhauser, E. B. D. (1946). Amer. J. Roentgen., 56, 1

Peacock, T. B. (1860). British and Foreign Medico-Chirurgical Review, 25, 467.

Perlman, L. (1944). Amer. Heart J., 28, 24.

Reifenstein, G. H., Levine, S. A., and Gross, R. E. (1947). Ibid., 33, 145.

Rooke, E. J. (1938). Brit. med. J., 1, 564.

Schwartz, E. R., and Tice, G. M. (1939). J. Kansas med. Soc., 40, 330.

Sheldon, W. (1932-3). Proc. Roy. Soc. Med., 26, 154. (1945). Diseases of Infancy and Childhood, 4 th ed., J. and A. Churchill, London, p. 407

Steele, J. M. (1941). J. clin. Invest., 20, 473.

Stewart, H. J., and Bailey, R. L. (1941). Ibid., $20,145$.

Thomson, A. P., and Lamb, F. W. M. (1929). Arch. Dis. Childh., 4, 377.

Wilkinson, K. D. (1932-3). Proc. Roy. Soc. Med., 26, 1537.

White, P. D. (1931). Heart Disease, Macmillan, New York. 


\section{APPENDix OF CASE Notes}

Case 1, aged 7 (1932). This boy had whooping-cough and measles and several attacks of bronchitis, and his first school medical examination without comment on his heart. When he was 6 , his doctor recorded an aortic systolic murmur. When 7 he was $\mathrm{n}$ the Brook Hospital and Dr. Young noted that his murmur had not changed during his attack of scarlet fever and sent him to outpatients with the suggestion that he might have coarctation.

He was found to have a rough aortic systolic murmur and thrill and a soft aortic diastolic murmur, both best heard to the left of the mid-line. A systolic murmur could be heard at the apex also and the diastolic was more rumbling. The blood pressure in the arms varied between 140-160 systolic and 55-85 diastolic, the latter being somewhat difficult to determine at times. In the legs it was 100/50 and the femoral pulses were hard to feel.

There was visible arterial pulsation round the scapulæ and shoulders and rib-notching on X-ray, though this was faint (see Fig. 3). The left ventricle seemed slightly hypertrophied (see Table I) and the aortic knuckle was not prominent. The diagnosis of coarctation of the aorta seemed conclusive, though there was some doubt whether he had in addition rheumatic valvular disease (A.S. and A.I., and possibly M.S.) or perhaps regurgitation from bicuspid aortic valves with some added stenosis.

During that winter he had some attacks of bronchitis at home, and when seen in March 1933, had a small right-sided pleural effusion. He made a rapid recovery in hospital and the fluid disappeared in three weeks. The general physical signs were unchanged: the collateral circulation seemed more obvious though pulsation in the femorals and abdominal aorta was still noted.

During the next three years he kept well, but in July 1936, when 11 years old, was readmitted with rheumatic pains, loss of weight, and increasing dyspnœa. Comparing his condition with four years before, the systolic blood pressure and the size of the heart relative to the chest seemed to have increased a little (see Table I). The rib-notching and the collateral circulation were more obvious.

His illness need not be detailed, but after ten days the temperature rose to $104^{\circ}$ and continued about $101^{\circ} \mathrm{F}$. for five weeks. Rheumatic carditis and infective endocarditis were considered and the former was confirmed by the occurrence of rheumatic nodules and the development of pericarditis with effusion, the transverse diameter of the heart shadow increasing from 14.0 to $17.0 \mathrm{~cm}$. (see Fig. 3). He made a gradual recovery, but from this time onwards he was more breathless and complained of pains in the legs and bronchitis from time to time.

He was last examined in 1938 when he was 13 . The apex beat was more heaving and the diastolic murmur was a little louder, both at the base and in the mitral area. The systolic pressure and the size of the heart had again increased a little (see Table I), the pressure in the arms being 165/60 and in the legs 110/?. The rib-notching was slightly deeper and more clear-cut.

In this boy as he grew from 7 to 13 years of age the heart increased in size from 11.5 to $15 \mathrm{~cm}$. with very little increase in the size of his chest or general development. His murmur also increased, but this and some of the increase in the size of his heart may have been due to the complication of his rheumatic carditis. The blood pressure, however, rose from 142/70 to $165 / 60$ (probably with a greater degree of aortic regurgitation) and the signs of the collateral circulation increased, though the ribnotching did not increase so much as in some.

Case 2, aged 7 (1933). This boy was seen because he did not seem to have regained his normal health after two attacks of pneumonia the year before. There was a rough systolic murmur at the base and the blood pressure was 140/90. He was taken into hospital to exclude infective endocarditis or nephritis. There was, however, no pyrexia and the urine was normal.

One of us (S. S.) already wished to diagnose coarctation of the aorta on a poor femoral pulse, some visible arterial pulsation round the scapula, and a suspicion of rib-notching (see Fig. 4). These signs were at this stage so slight that the other was not convinced and wrote that the only certain findings were an average blood pressure of $147 / 85$ and a little enlargement of the left ventricle. A year later, however, this diagnosis was made with certainty as the average pressure was now 159/88 (170/95-150/80) and the collateral circulation was more easily seen.

By 1936, when he was 10, there had been no further increase in the blood pressure or in the size of the heart. His general condition was improved though he was a little breathless if he tried to keep up with the other boys at school. 
He was seen frequently during 1937 and many readings of the blood pressure were taken with an average figure of $176 / 95$. The collateral circulation was now more easily visible and palpable: the femoral pulse was very difficult to feel and the pressure in the legs was recorded as $110 / 60$; he had sometimes complained of aching in the legs. Rib-notching was more easily seen on X-ray (see Fig. 4). The basal systolic murmur was rather louder when he was lying than sitting and sometimes a systolic thrill could be felt.

He had been rather undersized but during 1937-9 and the first two years of the war when he was away in Devonshire he grew a good deal and developed generally. The blood pressure still continued to rise to $165 / 100$ in 1939 , to $180 / 100$ in 1940 , and to $210 / 110$ in 1942 . The size of the heart had increased from $10 \mathrm{~cm}$. in 1937 to $11 \mathrm{~cm}$. in 1940 .

By 1946 , when he was 20 , the signs of coarctation were typical and well-developed though he considered himself in good health and was working as a bank clerk. It was difficult to feel any pulsation in the femorals or abdominal aorta and the pressure in the arm seemed to have stabilized at 210/105. The collateral circulation was even more easily seen than four years before and was now visible over the front of the chest as well as along the lower costal margins. The rib-notching had increased and the arterial pulsation in the neck was now much more visible than when he was a boy. The murmurs had increased as well and systolic and diastolic murmurs could be heard both at the apex and at the base with a long systolic thrill at the base. Originally there had only been a rather faint systolic murmur at the base which had gradually increased in loudness and in its area of distribution. The diastolic murmur had developed during 1936-40 (when he was from 10-14) and at first had seemed like a reduplicated second sound at the apex, so that taken alone this simulated the signs of mitral stenosis. The heart had also steadily increased in size from $9 \mathrm{~cm}$. at the age of 7 years, when there had seemed to be some ventricular enlargement only, to $11 \mathrm{~cm}$. in 1940 , and to $12.5 \mathrm{~cm}$. in 1946 , when there was a general increase in the size of the heart both to left and right, but the relative increase was not as much as the absolute increase, since the chest had also increased with his growth to a greater extent, i.e. from 19.5 to $29 \mathrm{~cm}$. There were no further changes in 1947. He was one of the patients when bending down made the arteries in the back and side, previously only visible under the left scapula, much more obvious and widespread (see Fig. 2).

Case 3, aged 25 (1932). This woman had no complaints till after a stillbirth in her second pregnancy when she was 25 . She was then a little short of breath, and was found to have slight enlargement of her heart to the left and a blood pressure of 230/120. She was advised to take some extra rest and to have no more children.

Three years later she was seen again as she had become pregnant, and the correct diagnosis was made. The B.P. was 210/110; the heart was enlarged to the left $(13.5 \mathrm{~cm}$. m.t.d. in chest of $25 \mathrm{~cm}$.); and there was forcible pulsation in the neck, simulating aortic regurgitation, and a systolic murmur and thrill loudest at the base of the heart. A collateral circulation was demonstrated over the abdomen and round the scapulæ and there was notching of the ribs on X-ray examination. Her pregnancy continued normally and a living child was born at term.

She left London and was lost sight of till 1944 during the fourth month of another pregnancy. Her general condition had continued to be good, but the collateral circulation was now more striking than before and could not have been missed. The other physical signs were unchanged and the B.P. averaged 230/120 (the same as in 1933), falling to 190/100 when she had been in hospital some days. The femoral pulse was difficult to feel and the B.P. in the legs was 120/85. The heart seemed rather larger, $15.5 \mathrm{~cm}$. m.t.d. in a chest of $27.5 \mathrm{~cm}$., but this was due to displacement owing to the pregnancy (see later and Fig. 6).

The cardiogram showed left axis deviation and was otherwise normal though some records in 1936 had shown some inversion of T III.

She was readmitted for her confinement in May 1945, aged 38, and the average of many blood pressure readings was 235/118 in the right arm and 220/112 in the left arm. Her renal function tests had been normal some months before, but as signs of toxæmia developed a healthy premature infant was delivered by Cæsarean section. Some urinary infection cleared up and she made a good recovery and was discharged home with a blood pressure averaging about 205/109.

In 1947, when she was 40 , she was in good health and doing most of her ordinary housework. The B.P. at an outpatient visit was $240 / 120$. The heart was very little larger than in 1935 , only $14.5 \mathrm{~cm}$. 
in a chest of 25.5 against $13.5 \mathrm{~cm}$. in a chest of $25 \mathrm{~cm}$. The collateral circulation in the back became much more obvious on bending.

In this case, in spite of a blood pressure of $230 / 120$ when she was 25 , the patient was in good health when 40 , and able to go through a pregnancy when 38 years old. There had been no further rise in her blood pressure and only a slight further increase in the size of the heart.

Case 4, aged 17 (1935). This girl came to hospital because of a hoarse voice, which had been getting worse for some time; it had not been improved by tonsillectomy when she was 10. Pulsation in the neck was noted then and had got worse since she was 14 , but she had no other symptoms and had played all games at school. Her heart had not been mentioned till she was 14, though she had been under observation because of her nose and throat for six years.

Mr. Mollison reported that the left vocal cord moved less well than the right. Her face looked bloated and she said that her face and lips often swelled up in the morning. There seemed a large pulsatile swelling low down in the neck on the right side. Because of this and the most unusual degree of pulsation on the right side of the neck it was thought at first that she might have an angioma acting like an arterio-venous aneurysm, but in view of the murmurs and other findings this was probably due to aortic incompetence and abnormal vessels from the right side of the arch (see Fig. 6) with a considerable collateral circulation through the thyroid.

She had systolic and diastolic murmurs loudest in the pulmonary area with a systolic thrill. The heart was enlarged to the left and the B.P. was 220/95 in the arm and 140/90 in the leg. No collateral circulation was seen as she was well-covered but it was easily felt. X-ray showed notching of the ribs, an absence of the aortic knuckle, and an extra shadow above the arch of the aorta below the right clavicle (? abnormal arterial branches).

The right pulse seemed stronger than the left and though the readings were variable they averaged $205 / 95$ in the right and 190/90 in the left arm.

She was seen several times between January and August and said she was well but perhaps a little more breathless. In December she was admitted to St. Olave's Hospital and died in a few days. The diagnosis made was "aortic incompetence and pneumonia," but unfortunately there was no necropsy.

Case 5, aged 19 (1937). This boy had been able to do a good deal without dyspnœa, but for four months had noticed increasing fatigue, especially after gymnastics, and headaches. There was increased pulsation in the neck and the collateral circulation was easily seen. Rib notching was conspicuous.

The blood pressure was sometimes as high as 200/130. The right pulse was felt more easily than the left and the average pressure was $180+107$ in the right, and 167/102 in the left arm. The femoral pulse could not be felt. 'There was no enlargement of the heart (see Table I and Fig. 8). There was a loud systolic murmur at the base, faintly heard towards the apex, but no thrill.

He was seen again in 1947, aged 29. He had passed into the R.A.F. without comment, graded A1, and had served 6 years, mainly doing clerical work in the Middle East, but taking part in all physical exercises and keeping very fit. His heart condition was noted-for the first time in the R.A.F.- and correctly diagnosed on demobilization. His only symptom was tiring too easily after exertion.

The collateral circulation in the back was perhaps less easily seen than in 1937, but over the abdomen it was very striking. The notching of the ribs was a little deeper and more clear cut (see Fig. 8).

As before the right pulse was more easily felt and the pressure was 200-175/120 in the right and $180-170 / 110$ in the left arm. Pulsation could not be felt in the abdominal aorta and barely in the femorals and the blood pressure in the leg was 115/?.

There was no enlargement of the heart and no change in its shape, the bulge in the region of the aortic knuckle being probably due to the enlarged subclavian artery. The systolic murmur at the base was still present, but was fainter and almost insignificant and was certainly much less than ten years before. The electrocardiogram showed no left ventricular preponderance, but slight widening of $S$ in all leads: all T waves were upright though T III had been inverted in 1937 . This was another case where bending down increased the collateral circulation and made it much more visible (Fig. 2). 
Case 6, aged 13 (1938). This boy was sent to hospital because of the undue pulsation that had been noted in his neck. He admitted to some recent dyspnœa but said that till recently he had been able to play all games without difficulty.

There was striking pulsation in the suprasternal notch and the blood pressure was about $210 / 80$ in both arms and 115 in the legs with a poor femoral pulse. Some collateral circulation was found with difficulty but only over the back; there was slight rib notching.

The heart was just enlarged, and there were loud systolic and diastolic murmurs at the base, so that he probably had aortic regurgitation as well as the coarctation.

He was seen again in 1947, aged 22 years. He was well built and of normal height and had been passed into the Navy during the war without comment. After some months, however, a medical orderly had drawn the doctor's attention to the pulsation in the neck and he had been discharged from the service. He had since worked regularly as an engineer, but admitted to some breathlessness with heavier exertion.

The physical signs were in general the same though there had been some increase. The pulse and blood pressure were the same in both arms falling from 230 to 195/85; it was difficult to feel any pulse in the abdominal aorta or femorals and the pressure was 125. The pulsation in the neck was perhaps even more striking, the collateral circulation was still seen and felt only after a careful search, but it could now be found along the sternal border as well: rib notching was moderate.

The heart had increased in size to $15.7 \mathrm{~cm}$. in a chest of $28 \mathrm{~cm}$. and the enlargement was mainly of the left ventricle (Fig. 5). An apparent aortic knuckle was probably the subclavian artery. The systolic and diastolic murmur at the base of the heart seemed louder and could also be heard at the apex, the former murmur suggesting that perhaps the degree of regurgitation had increased from progressive atheromatous changes, though there was no increase in pulse pressure to confirm this. The aortic second sound seemed accentuated and there was a long systolic thrill at the base. There was also a diastolic shock on palpation in the aortic area.

The cardiogram now showed T I inversion as well as the T II and T III inversion that had been present in 1937. As there was a large R III with no S III it was nearer right than left ventricular preponderance but was really of the $R R R$ type. These findings with the aortic diastolic murmur left some doubt as to what lesion was present as well as the coarctation: in spite of the cardiograms aortic regurgitation seemed the most likely.

Case 7, aged 36 (1940). He was rejected for the Navy at 20 because of his heart. He continued with heavy work although he was a little short of breath. A year before he had been giddy and had become unconscious for an hour-an episode suggestive of a congenital cerebral aneurysm. He was a healthy well-developed man with a little enlargement of the heart to the left, and a fairly loud and widely conducted systolic murmur. There was forcible pulsation in the neck and a poor femoral pulse. The blood pressure was 260/120 in the arms and 160/120 in the legs. Arterial pulsation was clearly felt down the vertebral border of the scapulæ and wide shallow notches were seen in the posterior part of the 3rd to 7th ribs on the right side and the 4th to 9th ribs on the left side. We are indebted to Dr. W. Gover of St. Leonards for details of this case. It has not been possible to trace him.

Case 8, aged 30 (1942). This officer was seen after pneumonia because of a harsh systolic murmur at the base of the heart. The femoral pulse was poor and the blood pressure was 190 in the arms and 120 in the legs. There was a collateral circulation round the scapulæ. X-ray showed no general enlargement of the heart, but, as usual, some rounding of the left ventricle, an absence of the aortic knuckle, and a moderate degree of rib-notching. He complained of no symptoms and has not been seen since.

Case 9, aged 29 (1944). A serving gunner was admitted with a minor pyrexial attack and was thought to have had nephritis as the blood pressure was found to be 220/130. He had led a normal life with no symptoms. We were asked to see him because of the widely distributed systolic murmur. The difficult of feeling the femoral pulse (with a blood pressure in the legs of 135/? 85) pointed to the diagnosis of coarctation and this was confirmed by notching of the ribs on X-ray examination. No other evidence of the collateral circulation was seen, but perhaps it was not searched for thoroughly enough. There was no general enlargement of the heart. 
Case 10, aged 30 (1946). A doctor consulted us about his high blood pressure which had been found when he was rejected for life insurance four years before: he thought it had been about 150 and once 170, and rather high (135-140) at 21 at a routine examination as a medical student. He knew he had a systolic murmur since childhood and had not been allowed to play football, but had not been short of breath climbing and had led a normal life otherwise. In 1944 he was rejected for the South African Army because his blood pressure was 175/90 and on one occasion 210: his renal function was fully investigated and found to be normal.

In 1946 the blood pressure was $210-190 / 110$ in the arms and about 120/80 in the legs. (Subsequently, resting in bed before his operation it was $170 / 100$ in the arms and 100/75 in the legs.) There was a rough systolic murmur in the second and third left intercostal spaces, but no thrill: it was also heard in the back. Apart from rib-notching the only obvious collateral circulation was one artery round the umbilicus (which had probably been mistaken for a vein) but arterial pulsation was increased in the neck and could also be felt over the left costal margin and below the right scapula. His heart was not enlarged; the left ventricle was a little rounded, but would probably have passed as normal without comment.

He has since had a successful operation by Dr. Crafoord in Stockholm (October 1946). No details of this are given as he will presumably be reported by Dr. Crafoord. Six months after the operation he was leading a normal life without symptoms and the blood pressure was 160-150/90-85 in the arms and 140-145/? 90-85 in the legs. The systolic murmur had greatly diminished and become quite insignificant. All signs of the superficial collateral circulation had disappeared: he stated that the arterial pulsation round the umbilicus had disappeared within a few days of the operation.

Case 11, aged 17 (1946). A bank clerk was sent to hospital because of the findings at a medical board. He admitted to no symptoms except trifling breathlessness compared with his friends, but his last year at school he had been told there was a murmur and had been stopped playing games. The heart was somewhat enlarged to the left with a rounded left ventricle and with a systolic murmur in the third intercostal space just to the left of the sternum, also well heard in the back, and a diastolic murmur in the aortic area. There was also a very slight systolic thrill at the base. The blood pressure in the arms was $195 / 100$ and $130 / 90$ in the legs. There was striking pulsation in the neck and a collateral circulation round the scapulæ. Radiography showed notching of the ribs and an absence of the aortic knuckle (see Fig 7).

A year later he felt in good health and there was no significant change in the physical signs. The collateral circulation in the back was greatly increased when he bent forward.

Case 12, aged 33 (1946). A Canadian was examined for life assurance before starting work in West Africa. He had led a very active life including boxing, rugger, and ice-hockey without any symptoms, but after completing a battle course in 1943 he was told his blood pressure was too high to continue. In 1946, the forcible pulsation in the neck was very obvious, but the femoral pulse was hard to feel: his blood pressure was 210/95, falling to 185/85 after resting, in the arms, and about 140 in the legs. There was a basal systolic murmur which was also heard in the back, but no thrill was felt. His heart was just enlarged clinically but an X-ray was not available. No collateral circulation was noted, apart from the extreme pulsation in the neck.

Case 13, aged 27 (1946). An ex-soldier, who had served six years and been a physical training instructor part of the time without any symptoms found himself tired in his civilian work as a painter and had occasional headaches. His doctor found a raised blood pressure and referred him to hospital.

Although the blood pressure was 195/105 when first seen, and 165/92 as the average of many readings when he was in hospital, the femoral pulse was hard to feel and the blood pressure in the leg was about 130. X-ray confirmed notching of the ribs with some enlargement of the heart (Fig. 5) and with difficulty some arterial pulsation could be felt.(but not seen) below one scapula. He had a systolic murmur at the base (which could be heard in the back also) but no thrill, and a house-physician and presumably the army doctor had not thought it of any special importance. On careful questioning he admitted that he had had pains in the legs during longer marches in the army. He was re-examined a year later. He felt better but there was change in the physical findings. Bending forward demonstrated an increase in the collateral circulation. 
Case 14, aged 18 (1946). A young man was sent by a recruiting medical board because of a systolic murmur. He had had a successful series of operations for hypospadias, and had been sent to hospital about his heart when 16, but no details were available and he had been allowed to continue his work. He had played games without any undue dyspnœa.

There was a rough systolic murmur at the base with a faint systolic thrill. There was no enlargement of the heart. There was forcible pulsation in the neck and a blood pressure of $165 / 105$ in the arms: the femoral pulse was hard to feel and no blood-pressure reading could be obtained in the legs. No collateral circulation could be seen, but abnormal pulsation could be felt at several points. Coarctation of the aorta was diagnosed and he was placed in Grade IV.

A year later, to our surprise he was found serving in a parachute regiment and was carrying out his duties without symptoms. No enquiries were made as to how he had joined the army. The physical signs were much the same and the blood pressure was 170/110 in the arms and could not be obtained in the legs. Bending down showed up the collateral circulation well. X-ray examination showed a high degree of notching and scalloping of the ribs (see Fig. 7) and confirmed the absence of any enlargement of the heart though the left border was a little rounded.

Case 15, aged 26 (1947). This man served in the Navy without symptoms, but was told there was something the matter with his heart when he was demobilized. He was sent to hospital by his factory doctor because of an aortic diastolic murmur. He had a systolic murmur to the left of the sternum with a systolic thrill best felt above the clavicles and a soft aortic diastolic murmur to the right of the sternum. His heart was not enlarged and the B.P. was 160/105. He had never complained of any symptoms but said that when he was about 9 years old there had been some comment on his heart at school.

For some reason he escaped X-ray examination and, although the raised blood pressure with a relatively high diastolic pressure without any enlargement of the heart, together with a poor femoral pulse, made coarctation seem likely, rheumatic aortic incompetence and stenosis was thought possible because no evidence of a collateral circulation was found (this was in 1946 before Cases 10-14 were seen).

A year later in discussing the possibility of coarctation, we demonstrated that no collateral circulation could be seen in his back when he was standing erect, but that as soon as he bent forward many small arteries stood out and became most obvious over the back and sides of the chest wall (Fig. 1). An X-ray film then confirmed the diagnosis by showing deep notching of several ribs. The-heart was not enlarged (m.t.d. $13.5 \mathrm{~cm}$. in a chest of $29 \mathrm{~cm}$.). The blood pressure varied between $185 / 120$ and $155 / 95$ in the arms and $110 / 90$ in the legs. 